\title{
Recent advances in surface and interface engineering for electrocatalysis
}

\author{
Chengming Wang*, Song Bai, Yujie Xiong\# \\ Hefei National Laboratory for Physical Sciences at the Microscale, iChEM (Collaborative Innovation Center of Chemistry for Energy Materials), and School \\ of Chemistry and Materials Science, University of Science and Technology of China, Hefei 230026, Anhui, China
}

A R T I C L E I N F O

Article history:

Received 29 March 2015

Accepted 28 May 2015

Published 20 September 2015

\section{Keywords:}

Synthesis

Surface engineering

Interface engineering

Electrocatalysis

Hybrid structure

\begin{abstract}
A B S T R A C T
Electrocatalysis has attracted extensive attention for its promise in converting chemical energy of fuels and oxidants into electrical energy. In this review, we use our recent progress in electrocatalysis as examples to demonstrate how to rationally design and fabricate noble metal-based nanostructures. This information will enable the optimization of nanocatalysts, in terms of both cost and performance, from the viewpoint of surface and interface engineering. We first outline the key features related to surface and interface that may significantly impact on electrocatalytic performance. We then summarize various approaches to surface and interface modulations by highlighting materials synthesis, design and electrocatalytic performance for specific cases. Finally, we propose the challenges and opportunities to perform materials design for electrocatalysis from the aspect of surface and interface engineering.
\end{abstract}

(C) 2015, Dalian Institute of Chemical Physics, Chinese Academy of Sciences. Published by Elsevier B.V. All rights reserved.

\section{Introduction}

Grubb [1] first put forward the concept of electrocatalysis in 1963, which he defined as the enhancement of the rate of an electrochemical reaction by a substance. Electrocatalysis has experienced great progress and gradually developed into an interdisciplinary science and comprehensive technology that involves electrochemistry, materials science, surface science, catalytic science and many other branches of science. Electrocatalysis plays an indispensable role in industrial and agricultural production, national defense, economic construction, energy development and environmental protection [2-10]. At present, electrocatalysis, as an essential and effective means for an electrochemical and catalytic united-technology, is wide- spread, and has been applied to the controllable synthesis and functional assembly of nanomaterials [11-14], micro-nano fabrications and electronic devices [15-20], metal processing, forming, plating and finishing [21-25], organic chemical reactions [26-28], nitrogen cycle and chlor-alkali industry [29-31], electrochemical luminescence and photosensitive measurement [32-34], electrochemical sensors and biosensors [35-38], electrochemical engineering for cell biology and medical therapy [39-43], electrochemical process of detection and analysis [44-47], and organic waste degradation and wastewater treatment [48-51]. In particular, to alleviate and address the increasingly severe energy and environmental crisis, efforts have been intensively focused on electrocatalysis for energy development, conversion and storage, such as chemical batter-

\footnotetext{
* Corresponding author. Tel: +86-551-63606447; Fax: +86-551-63606657; E-mail: chmwang@ustc.edu.cn

\# Corresponding author. Tel/Fax: +86-551-63606657; E-mail: yjxiong@ustc.edu.cn

This work was supported by the National Natural Science Foundation of China (21101145, 21471141), the Recruitment Program of Global Experts, the CAS Hundred Talent Program, the Anhui Provincial Natural Science Foundation (1508085MB24), and the Fundamental Research Funds for the Central Universities (WK2060190025, WK2310000035).

DOI: 10.1016/S1872-2067(15)60911-1 | http://www.sciencedirect.com/science/journal/18722067 | Chin. J. Catal., Vol. 36, No. 9, September 2015
} 
ies or metal-air batteries [52-55], super-capacitors [56-59], solar water splitting cells [60-63], and low-temperature fuel cells [64-69].

The great advances and broad applications of electrocatalysis are greatly facilitated by the design and controlled synthesis of metal nanocatalysts [52-69]. The metal nanocatalysts (especially transition metal and noble metal nanocatalysts) have been widely used as electrocatalysts, mainly because the transition metals and noble metals may provide $d$-orbital lone-pair electrons as nucleophilic reagents or provide empty $d$-orbitals as electrophilic reagents in chemical reactions. The metals may coordinate with alien species to form intermediates to reduce the reaction activation energy, eventually promoting the catalytic reaction. Meanwhile, they may also provide adjustable $d$-band locations and electronic structures by tuning their composition and structural features, which alters the adsorption and stripping abilities of reactants/products on their surface/interface and further improves the activity, selectivity and stability of nanocatalysts [70-78]. Thus far, various unique transition/noble metal nanocrystals and their hybrid nanostructures have been synthesized through a variety of gas-phase, solid-phase and solution-phase synthetic methods as well as loading and assembly techniques. In particular, the solution-phase synthesis provides a versatile platform for controlled synthesis by manipulating the nucleation and growth process that involves atom generation, nucleation, seed formation, seeding growth and/or epitaxial growth. The experimental parameters that can be tuned in a reaction system include precursors, reducing agents, capping agents, etching agents, solvents, temperature and many others. Furthermore, combined with post-synthesis techniques, such as etching, loading and assembly, the synthesis can yield metal nanocrystals and their hybrid nanostructures with well-defined sizes, shapes and structures [72-78].

Noble metal catalysts (mainly Pt, Pd, Ru and Rh) with high activity, selectivity and stability are prevalent in catalysis and still cannot be completely replaced by other materials [79-82]. The major bottleneck limiting the catalytic applications of noble metals is their high cost and unsustainability owing to their relatively low abundance in nature. For this reason, an urgent challenge facing the human race is how to design, synthesize and assemble high-performance and low-cost metal nanocatalysts. In the past decade, great efforts have been made towards this goal, leading to numerous gratifying and encouraging achievements [72-82]. The catalytic properties of metal nanocatalysts are closely related to their shapes, structures, sizes and compositions that are essentially correlated with atomic arrangements, molecular adsorption and activation, electronic structures, charge transport, and other surface and interface features. Inspired by previous researches, we can simply define electrocatalysis as the heterogeneous catalytic reaction that occurs on the surface and interface of electrode materials and electrolytes [2-10,83]. Thus, surface and interface engineering is vital to the design, synthesis, construction and optimization of metal nanostructures and their hybrid nanostructures.

Fuel cells (FCs) are a class of electrochemical power-generation devices which can directly and continuously convert the chemical energy of fuels and oxidants into electrical energy. Compared with other traditional power-generation devices, fuel cells have the merits of low noise, fast response, good modularization, high operation quality and high energy conversion efficiency and can adapt well to different load power requirements, waste-heat utilization and catalyst loading/manufacturing solutions [84-88]. Fuel cells can be classified as molten carbonate fuel cells (MCFCs), solid oxide fuel cells (SOFCs), alkaline fuel cells (AFCs), phosphoric acid fuel cells (PAFCs), and proton exchange membrane fuel cells (or polymer electrolyte membrane fuel cells, PEMFCs) according to the varied electrolytes used in the cells. Despite the difference in electrolytes, reactions at the anode and the cathode in all FCs are separated, in which ions move through the electrolyte while electrons transport along an external circuit. Among the five

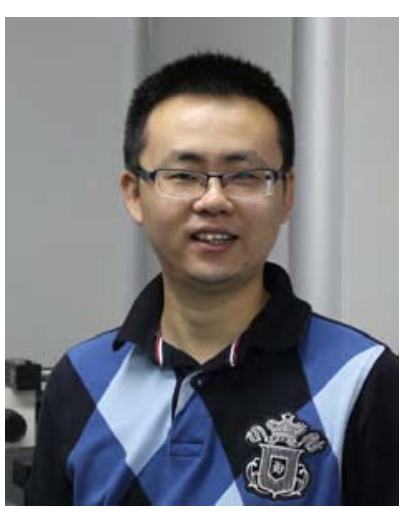

Yujie Xiong (University of Science and Technology of China) received the Young Chemist Award in 2013 and the Young Cutting-Edge Nanochemistry Researcher Award in 2014, which were presented by the Chinese Chemical Society. Professor Yujie Xiong received his B.S. degree in Chemical Physics in 2000 and Ph.D. degree in Inorganic Chemistry under the tutelage of Professor Yi Xie in 2004, both from University of Science and Technology of China (USTC). Prior to joining the USTC faculty as a full professor in 2011, he was the Principal Scientist and Lab Manager of the National Nanotechnology Infrastructure Network (NSF-NNIN) site at Washington University in St. Louis. He is serving as the Editorial Board members of five international journals such as Scientific Reports, the Board Committee member of International Academy of Electrochemical Energy Science (IAOEES), and the member of Young Chemist Committee of Chinese Chemical Society. He has received a number of other prestigious awards, including the CAPA Biomatik Distinguished Faculty Award by the Chinese-American Chemistry \& Chemical Biology Professors Association (2015), the Outstanding Young Scholar Award by the Hong Kong Qiushi Science and Technology Foundation (2014), and the National Natural Science Award (Second Class) by the Chinese government (2012), and is among the "2014 Most Cited Chinese Researchers (Chemistry)" by Elsevier. His research interests include synthesis, fabrication and assembly of inorganic catalytic materials for energy and environmental applications. He has published more than 100 peer-reviewed papers in prestigious journals such as Science, J. Am. Chem. Soc., Angew. Chem. Int. Ed., Chem. Soc. Rev. and Adv. Mater. with over 9000 citations. 
types of FCs, the PEMFC is the most promising for efficient energy development given its high power density, small stack size, low cost, low operating temperature, fast response, high energy conversion efficiency and clean environment. It can additionally reduce or eliminate the need for thermal insulation, hydrogen storage and transportation, and safety protection [84-88]. As such, the electrocatalytic reactions related to the PEMFCs, such as the formic acid oxidation reaction (FAO), methanol oxidation reaction (MOR), oxygen reduction reaction (ORR), oxygen evolution reaction (OER) and hydrogen evolution reaction (HER), have naturally become the focus of research in recent years. In particular, surface and interface engineering for cost-effective anode or cathode electrocatalysts is the challenge for the emerging and burgeoning investigations on electrocatalysis for fuel cells [89-92].

In this review, some recent advances in the surface and interface engineering of noble metal-based nanostructures as well as their applications in electrocatalysis will be briefly introduced. The key factors to the design, synthesis and assembly of metal nanostructures and their hybrid nanostructures will also be simply outlined and discussed. We will use some of our representative cases in electrocatalysis as specific examples, with an emphasis on surface and interface engineering, to shed light on how to rationally design and fabricate these electrocatalytic nanostructures, and thus to achieve optimization of nanocatalysts in terms of both cost and performance.

\section{Key features of the surface and interface}

To rationally implement surface and interface engineering in the electrocatalyst design, an understanding of the effects of surface and interface on reactions is required. In this section, we highlight a few of the key factors that need to be taken into account when designing metal nanostructures and their hybrid nanostructures.

\subsection{Surface areas}

Heterogeneous catalytic reactions, including electrocatalysis, occur on the surface of catalysts, and as a result, a larger effective surface area should be advantageous for catalytic reactions. In principle, four different approaches can be employed to increase the effective surface area of a catalyst. The first method is to reduce the sizes of the catalyst particles, simply because a decrease in size can dramatically boost the surface-to-volume ratio. As a matter of fact, this is one of the main reasons for the widely used size-control strategy in heterogeneous catalysis. As the size of nanoparticles is reduced to $2 \mathrm{~nm}$, their surface-to-volume atomic ratio can be increased to $80 \%$ [93-96]. The second typical approach is to fabricate catalysts into thin-layer two-dimensional (2D) nanostructures, such as ultrathin 2D nanoplates or even atomically thin 2D nanosheets, which can significantly boost the surface-to-volume ratio of catalysts. Xie's group carried out systematic researches on the design, synthesis, assembly and application of 2D ultrathin nanostructures, including metal oxides and metal chalcogenides, which were proven to be useful for improving the specific surface area and active reaction sites of catalysts as well as their flexibility and dispersion [97-99]. Despite the fast development of 2D compound materials, the major challenge is to synthesize and stabilize 2D metallic nanostructures, as metal atoms have a strong preference to form close-packed crystal structures in three dimensions. Most recently, a number of research groups have made pioneering contributions to the controllable synthesis of Pd, Rh, Ru, Au, Ag, Pd@Ag and Pt-Cu nanosheets or nanoplates with catalytic and optical applications, which has increased the possibility of fabricating 2D metal nanostructures [100-108]. The third way is to increase the roughness of the catalyst nanostructures, and to form irregular surfaces with convex, concave, plicated or cracking rough nanostructures. Such unique structures with morphologies analogous to flowers, dendrites, multi-pods, tapers, stars, starfishes, cactuses and islands can naturally promote the effective surface area for catalytic performance enhancement [109-114]. The fourth common means is to manufacture hollow, porous or mesoporous nanostructures such as nanotubes, hollow nanospheres, nanoboxes, nanocages, nanoframeworks and metal-organic frameworks (MOFs). These structures with porosities can not only substantially increase the specific surface areas and number of active reaction sites, but also effectively accelerate the exchange and transportation of species on the catalysts [115-122]. In addition to borrowing porous structures from templates, such as MOFs, 3D nanoporous structures of noble metals and their alloys can be directly prepared towards electrocatalytic applications through different strategies including in-situ synthesis, electrodeposition, de-alloying, annealing, templating, galvanic replacement, and modification [123-135]. For instance, Ding et al. [128-135] have developed 3D nanoporous metal structures with a focus on gold and it alloys.

\subsection{Surface facets}

It is widely recognized that the catalytic properties of nanostructures depend on the type of surface facets [136-143]. According to Miller indices $\{h k l\}$, for a face-centered cubic $(f c c)$ crystal structure, surface facets can be classified as low-index facets including the three basic $\{111\},\{100\}$ and $\{110\}$ facets, and high-index facets $\{h k l\}(h \geq k \geq l>0)$ with at least one of the indices greater than unity (including $\{h k 0\}(h>k>0),\{h h l\}(h>$ $l>0),\{h k k\}(h>k>0)$, and $\{h k l\}(h>k>l>0))$ (Figs. 1(a), (b)). Various surface facets have different atomic arrangements, and the surface energy $(\gamma)$ follows the order of $\gamma\{111\}<\gamma\{100\}<\gamma$ $\{110\}<\gamma\{h k l\}$ at high-index facets. As a result, the research community faces a challenge-opportunity dilemma. On one hand, nanocrystals tend to form regular shapes (namely, tetrahedral or octahedral enclosed by $\{111\}$ facets, or Wulff polyhedra composed of multiple $\{111\}$ and $\{100\}$ facets) rather than nanocrystals with high-index facets to minimize surface energy. Thus, the formation of high-index facets on nanocrystal surfaces represents a formidable challenge. On the other hand, nanocatalysts with high-index planes usually exhibit enhanced activities, owing to their higher surface energy and lower coordinated atoms, relative to those close-packed low-index facets 
such as (111), (100) and (110) planes. Given this dilemma, the research community strives to tailor the surface structures of nanocrystals with low-index facets by controlling the nucleation and growth process through synthesis (Figs. 1(c)-(e)), and at the same time, develop nanostructures with high-index surfaces for more valuable and widespread applications. For example, CO adsorbed on Pt (111) terraces has a higher electrocatalytic reactivity compared to that adsorbed on either (110) or (100) steps [144]; it has been reported in 2007 that Pt low-index facets in the electrocatalytic formic acid oxidation reaction follow the activity order of $\mathrm{Pt}(100)<\mathrm{Pt}(111)<\mathrm{Pt}$ (110), and the activities of high-index facets, such as Pt (710), Pt (310), Pt (210) and Pt (520) with a large density of atomic steps and dangling bonds, are significantly higher than those of low-index facets [145].

The formation of surface facets is mainly determined by the surface energies, and thus can be altered by introducing foreign species into the synthetic systems, as the specific adsorption ability of species to the metal surface modifies the surface energies. It should be pointed out that the surface structure of a nanocrystal has a strong correlation with its particle size (namely, the length of edge) (Fig. 1(f)). Use of surface capping agents can tune both the facets and sizes of nanostructures in the synthesis. In the synthesis, one can control the growth rates of various facets by selecting appropriate surface capping reagents, regulating the "two rates" (i.e., nucleation and growth rates) and "two mechanics" (i.e., thermodynamic control or kinetic control), as well as inducing anisotropic growth or epitaxial growth to obtain various polyhedrons as well as 1D nanostructures (including nanowires and nanorods) and 2D nanostructures (including nanoplates, nanosheets and nanobelts) deviated from the Wulff polyhedra. Implementing oxidation etching or epitaxial growth in the synthesis, one can also achieve the preparation of novel nanostructures with

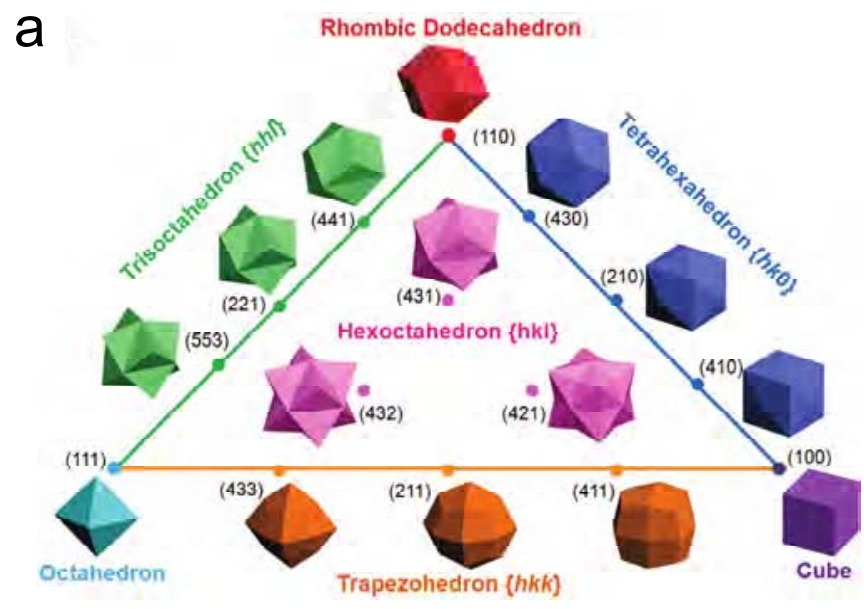

C
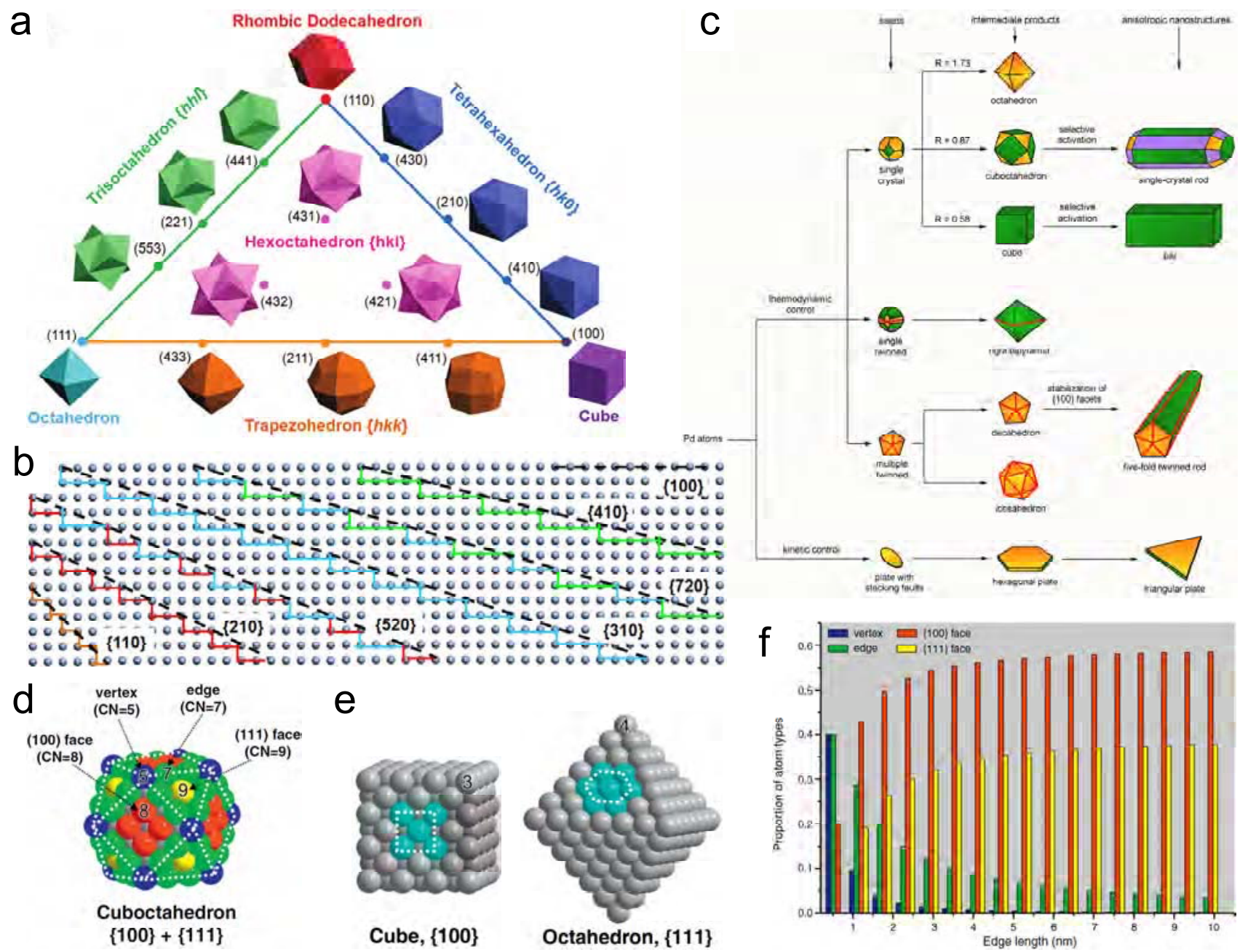

Fig. 1. (a) Triangular diagram showing $f c c$ metal polyhedrons bounded by different crystallographic facets. (b) Atomic models of two low-index $\{100\}$ and $\{110\}$ planes as well as five representative high-index $\{210\},\{520\},\{310\},\{720\}$ and $\{410\}$ planes viewed from the $<100>$ directions. The $h / k$ value of the $\{h k 0\}$ planes and the atomic length of the (100) terraces increase. (a, b) Reproduced with permission from Scheme 1 and Figure S8 (Supporting Information) of Ref. [137]. (c) Schematic illustration for the reaction pathways that lead to $f c c$ metal nanostructures with different shapes. Reproduced with permission from Ref. [138]. (d) Atomic model of a three-shell cuboctahedron, showing the different types of surface atoms and their coordination numbers. Reproduced with permission from Ref. [139]. (e) Atomic models of cubic and octahedral nanocrystals. (f) Proportions of different types of surface atoms (vertex, edge, and face) as a function of edge length for Au cuboctahedrons. (e, f) Reproduced with permission from Ref. [140]. 
high-index facets.

\subsection{Active sites}

The concept of "active sites", which was first introduced to heterogeneous catalysis by Taylor in 1925, has played an important role in explaining and understanding the nature of heterogeneous catalytic reactions [146]. The active sites, rather than all sites on the surface of catalysts, are responsible for catalytic reactions [97,147-150]. In general, the active sites of a catalyst are regarded as low-coordinated surface atomic sites, including the low-coordinated atoms at terraces, steps, kinks, edges, vertexes, corners, defects, vacancies, pits, and holes that often favor the catalytic reactions. The number of active sites heavily depends on the features of surface and interface, and has a key effect on the interactions of molecules and ions with nanocatalysts. First, active sites are strongly correlated with the surface roughness of a catalyst. A metal surface generally consists of two types of surface atoms: (1) well-embedded, predominant and stable equilibrated metal surface (EMS) atoms, and (2) protruding, low-population and high-energy metastable metal surface (MMS) atoms. The MMS atoms are prone to undergo reactions with the involved species at low potentials formulating the basis for pre-monolayer oxidation/reduction, which thus often function as surface active sites and play a vital role in surface/interfacial electrocatalysis [151-153]. Second, active sites are intuitively associated with the surface facets of a nanocrystal (Figs. 1(d)-(f)) [139,140]. The surface of a metal nanocrystal is enclosed by different types of atoms (including face, edge and vertex atoms) whose coordination numbers (CNs) follow the order of face $>$ edge $>$ vertex with the reverse order in terms of catalytic activity. For an $f c c$ metal nanocrystal, the faces of a perfect cube and octahedron are exclusively covered by $\{100\}$ and $\{111\}$ facets with square and hexagonal atomic arrangements, respectively. For different well-defined shapes, the variations in surface facets would alter the proportions of various surface atoms with different coordinated states, which also, in turn, affect the catalytic properties. Third, active sites are related to surface defects or vacancies. In principle, breaking chemical bonds to endow atoms with low-coordinated states is beneficial to creating active sites. For instance, defect or vacancy engineering on the basal planes of catalysts can increase the exposure of active edge sites by forming cracks on the surfaces, and as a result, may dramatically enhance electrocatalytic performance [154-157] Last, the number of active sites naturally depends on surface areas and particle sizes based on the discussion above (Figs. 1(d)-(f)).

\subsection{Interface structures for multicomponent systems (i.e., hybrid structures)}

Obviously, interfaces will be formed where different objects or phases contact each other. Thus, heterogeneous catalytic reactions can essentially be regarded as various interfacial effects. In terms of electrocatalysis, three interfaces need to be presumed and understood: the interface between electrolyte and catalyst, the internal interface between components in a catalyst with hybrid structures, and the interface between catalyst and electrode. In this review, we will limit our discussion to the internal interface in the catalyst, because this interface is a versatile center for engineering catalysts towards heterogeneous electrocatalytic reactions. As illustrated in Fig. 2(a), an interface is naturally formed between two components A and B around which a dynamic triple-phase structure involves the electron path, proton path and solution phase. Engineering the interface can potentially alter interfacial compositions and geometry structures, electronic structures and electron transport, proton transfer and species exchange, crystal structures and dangling bonds, Fermi levels and band alignments, atomic arrangements and coordination numbers, and selective adsorption and desorption, which all may have tunable and synergistic effects on the heterogeneous electrocatalysis occurring at the active sites of catalysts [158-166]. For instance, the dual-function active sites in Pt-Pd alloy nanopolyhedrons can enhance the electrocatalytic performance in the methanol oxidation reaction [164]; $\mathrm{Pt}_{3} \mathrm{Y}$ nanostructures can modify the electronic structure, $d$-band depth and surface adsorption ability of Pt, leading to improved performance in the ORR [165]; Pt-Co alloy nanowires, depending on their compositions and structures, can indeed serve as promising electrocatalysts with enhanced catalytic activity and improved durability for practical electrocatalytic applications [166].

Adding a new metal or other element into the electrocatalytically active metal (e.g., Pt and Pd) represents a powerful method to tune the electrocatalytic performance in various reactions. Thus far, the obtained bimetallic or multimetallic nanostructures, including alloys, can be mainly classified as a core-shell structure, subcluster structure, multishell structure and embedded structure according to their atomic locations (Fig. 2(b)) [167]. The interface engineering is usually accomplished through structure engineering and/or composition engineering on the components, constructing novel nanostructures for specific catalytic reactions.

In addition to the multimetallic structures, hybrid structures can also be formed between metals and other materials such as graphene and semiconductors. The metal-based hybrid structures (also called metal matrix nanocomposites, MMNCs) represent the most popular development direction in materials science, since the concept was put forward in 1984 by Roy et al. [168]. The hybrid structures can also be referred to assembly nanostructure and integrated nanostructure in terms of their preparation process and resulting configuration, respectively. From the viewpoint of synthesis, they can be made by the following approaches.

In-situ growth and coating: In-situ synthesis is a straightforward approach to prepare various metal-based hybrid structures, in which synthetic conditions, such as precursors, should be adjusted according to the specific situation [169-171]. In specific cases, coating can be achieved through electrochemical deposition, epitaxial growth and surface modification in aqueous-phase synthesis, or other synthetic methods such as gas evaporation, sputtering, sol-gel synthesis and microemulsion synthesis. Coating has played an effective role in 
a

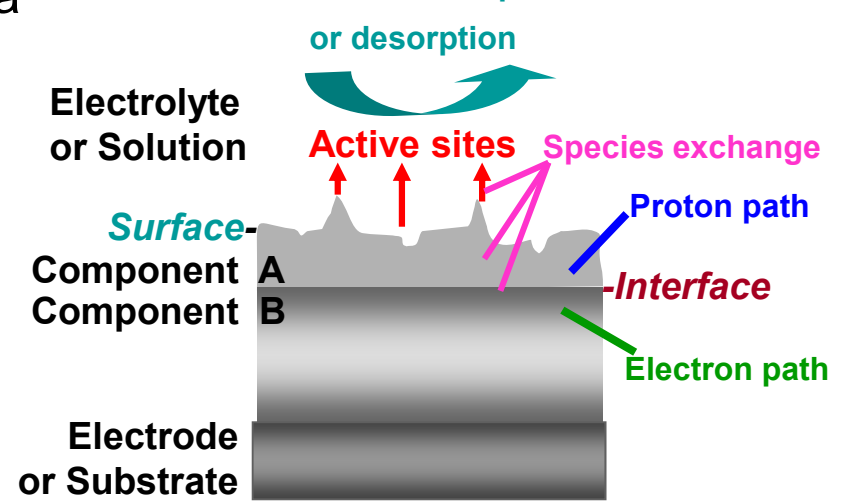

b

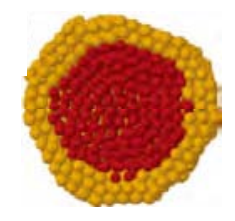

Core-shell

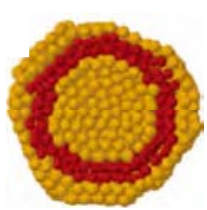

Multishell

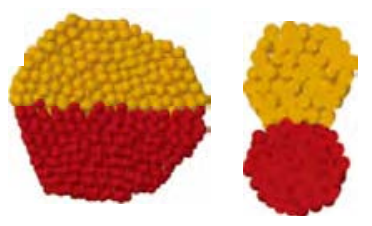

Subcluster

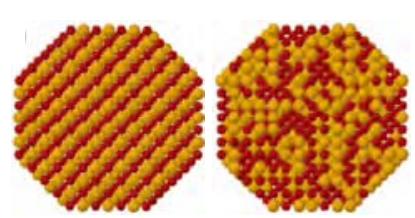

Embedded
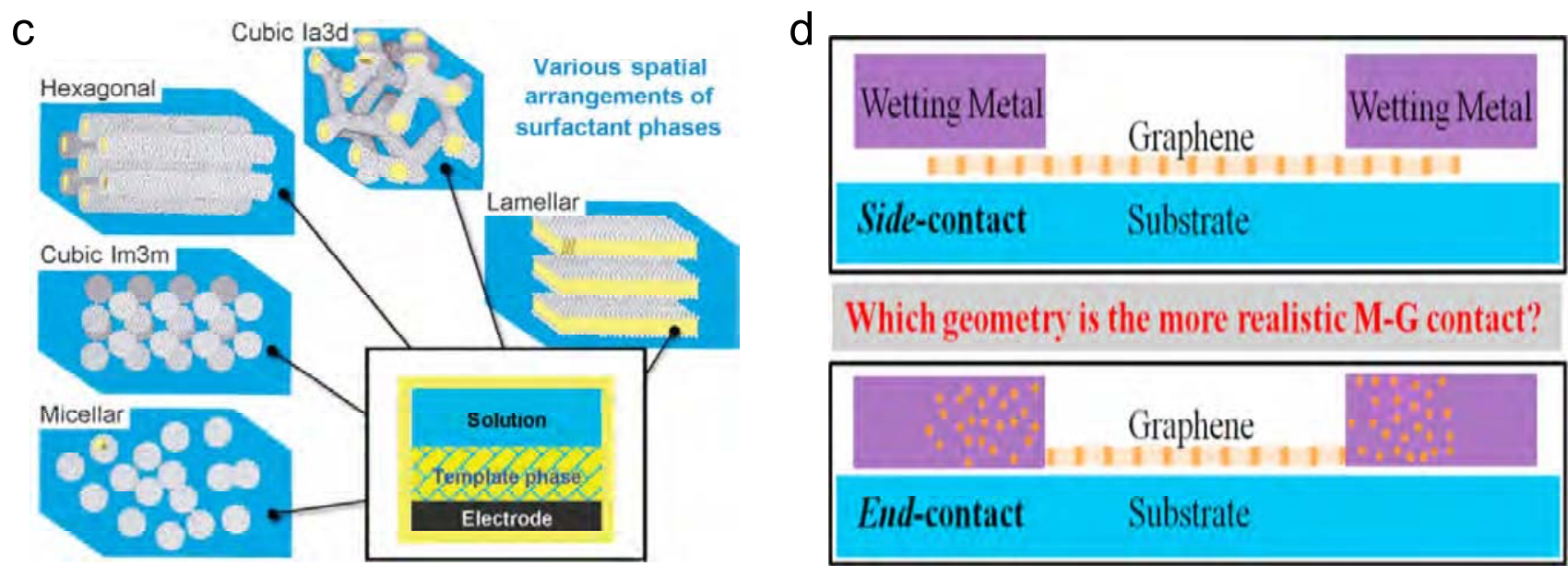

Which geometry is the more realistic M-G contact?

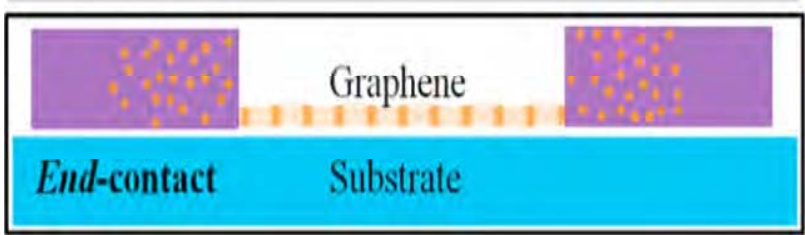

Fig. 2. (a) Illustration for an ideal simple triple-phase boundary structure where electron path, proton path and solution phases are presented together with active sites. (b) Schematic representation of various hybrid configurations: core-shell, subcluster, multishell and embedded structures in the cross-section view. Reproduced with permission from Ref. [167]. (c) Illustrative schemes of some surfactant assemblies and lyotropic liquid crystalline (LLC) phases that can be designed on electrode surfaces. For the top LLC cartoons, blue, white and yellow colors represent water domain, hydrophilic head groups and hydrophobic alkyl chains, respectively. Reproduced with permission from Ref. [181]. (d) Illustration for two types of realistic metal-graphene contact structures. Reproduced with permission from Ref. [191].

processing metal surfaces and assembling functional composites. Note that the coating approach has often been employed at the early stage of building metal-organic frameworks (MOFs) on electrodes [172-175].

Etching: The function of etching is to intentionally remove and subtract materials from existing structures. Etching has been widely employed to prepare unique well-defined or ordered metal-based hybrid nanostructures including low- or high-index, porous, mesoporous, hollow or framework structures [176-180]. Among the obtained structures, the hybrid structures, with porosity and hollow nature, are particularly active to heterogeneous electrocatalysis given their improved solubility and dispersion, larger surface areas as well as increased number of surface active sites and dangling bonds. By building various spatial arrangements of surfactant phases on the electrode surface (Fig. 2(c)), proton transfer and species exchange can be facilitated [181-184].

Loading: Loading metal nanostructures on support materials has played an important role in the fabrication of metal-based hybrid structures in recent years. 2D materials, such as graphene (including $\mathrm{N}, \mathrm{P}$ and $\mathrm{O}$ doping), g- $\mathrm{C}_{3} \mathrm{~N}_{4}$, hexago-
nal-BN and transition metal chalcogenide nanosheets, which possess unique periodic plane structures and excellent physical properties (e.g., large specific surface area, high tensile strength and elastic modulus, and/or high thermal conductivity and electronic mobility), can act as the support materials for manufacturing such unique hybrid structures. These hybrid nanostructures have been used in electrocatalytic reactions, such as FAO, ORR, OER and HER, and show high activity and high stability in contrast to bare metal nanocrystals. Graphene is a typical representative as a support to construct metal-graphene hybrid nanostructures [185-190]. Despite the great progress, there are still many issues that need to be addressed such as geometry optimization for realistic metal-graphene contact. In 2014, Wallace et al. proposed two contact models, side-contact model and end-contact model, for metal-graphene interfaces (Fig. 2(d)). They showed that Pdand Ti-graphene hybrid structures adopted the end-contact model owing to the formation of $\mathrm{Pd}$ - and Ti-carbides associated with $\mathrm{C}-\mathrm{C}$ bond breaking in graphene [191]. This work provides important references and insights for assembling the metal-graphene hybrid structures on electrodes. 


\section{Surface engineering for electrocatalysts}

In this section, we will overview our recent progress on surface engineering for electrocatalyst design in terms of surface facets. Thus, the discussions of materials design, synthesis and electrocatalytic performance are sorted into low-index facets and high-index facets.

\subsection{Low-index facets}

The low-index facets include $\{111\},\{100\}$ and $\{110\}$ facets with their surface energies in the order of $\gamma\{111\}<\gamma\{100\}<\gamma$ $\{110\}$. Owing to their different atomic arrangements on a surface, various low-index facets exhibit differentiated activities in electrocatalysis. Certainly, the activities of different surface facets relative to each other are highly dependent on the types of reactions as well as the reaction media (e.g., ORR in $\mathrm{H}_{2} \mathrm{SO}_{4}$ versus $\mathrm{HClO}_{4}$ ). Based on the established synthetic methodology for $f c c$ metal nanocrystals $[72,78,138]$, we have been able to successfully engineer the low-index facets exposed on the surface of well-defined metal nanocrystals. We have performed studies on the surface engineering of low-index facets from three angles.

The first method involves the acquisition of metal (e.g., Pd) nanocrystals bound by different low-index facets with comparable sizes, which allows us to investigate their facet-dependent effects free from size-effect interference. For instance, we have obtained two types of well-defined Pd nanocrystals (namely, Pd nanocubes enclosed by $\{100\}$ facets and Pd octahedrons covered by $\{111\}$ facets) by tuning the reaction kinetics. The sizes of the two Pd nanostructures are precisely controlled by employing oxidative etching or adjusting the reaction time. The study clearly demonstrated that the Pd $\{100\}$ facet is significantly more active than $\mathrm{Pd}\{111\}$ in electrocatalytic formic acid oxidation [192,193]. It is believed that this catalytic performance difference can be ascribed to $\mathrm{Pd}\{100\}$ having a higher ability to activate oxygen species. Similarly, when Pd nanocrystals are implemented in glucose oxidation, the Pd nanocubes with $\{100\}$ facets exhibit dramatically higher activity than the $\{111\}$-octahedrons at similar sizes [194].

The second study is to maintain the same low-index facets but tune the particle sizes of metal nanocrystals, providing a platform for investigating size effects. Two approaches can make it possible to tune the sizes of metal nanocrystals (e.g., Pd nanocubes, octahedrons and cuboctahedrons): controlling the number of seeds formed in the nucleation stage by employing oxidative etching [195], or manipulating the kinetics of atomic addition by adjusting the feeding rates of precursors with a syringe pump [196]. The particle sizes can also be controlled by adjusting the reaction time or performing a seeding process; however, the applications of these two synthetic methods are limited by shape inconsistency and low product yield, respectively. Enabled by this size control, we have been able to observe that the activities of $\mathrm{Pd}$ nanocubes in electrocatalytic formic acid oxidation increase with the shrinkage of particle sizes mainly as a result of the boosted surface-to-volume ratios [193]. This size control has provided an excellent platform for the investigation of size-dependent catalytic activities in various reaction systems such as the catalytic efficiency improvement in the Heck coupling reaction by reducing the sizes of $\mathrm{Pd}$ octahedrons [196].

The third investigation involves evaluating the effect of electrical contact between low-index facets and electrodes on electrocatalytic performance. To perform this study, we have successfully achieved the gradual evolution from Pt multipods to Pt multicubes by increasing the coverage of $\{100\}$ facets on the surface, all of which show significantly higher ORR activities than Pt nanocubes despite their $\{100\}$ coverage (Figs. 3(a)-(e)) [197]. This shape evolution takes place through a simple $\mathrm{Ni}^{2+}$-underpotential deposition and galvanic replacement process. The resulting Pt multicube is analogous to an assembly of multiple cubes enclosed by $\{100\}$ facets but contains a tiny junction area with $\{311\}$ facets between the adjacent cubic components. In sharp contrast, the Pt multipods are enriched with $\{311\}$ high-index facets. Such $\{311\}$-to-\{100\} facet evolution is mainly caused by the fast growth on (111) steps in the presence of Ni (Figs. 3(f)-(h)). Despite their high $\{100\}$ coverage, the Pt multicubes exhibit excellent ORR performance. The half-wave potential $\left(E_{1 / 2}\right)$ value of Pt multicubes in ORR has been determined to be as high as $0.955 \mathrm{~V}$, which is comparable to $0.957 \mathrm{~V}$ of Pt multipods and is $56 \mathrm{mV}$ higher than that of $\mathrm{Pt}$ nanocubes (Fig. 3(i)). The mass and specific activities of $\mathrm{Pt}$ multicubes reach $0.562 \mathrm{~A} / \mathrm{mgt}_{\mathrm{Pt}}$ and $0.729 \mathrm{~mA} / \mathrm{cm}^{2}$, which are about 5.1 and 6.7 times higher than those of Pt nanocubes, respectively (Fig. 3(j)). The blank CVs verify that the Pt multicubes have distinct (100) features similar to those for the $\{100\}$-enclosed Pt nanocubes (Fig. 3(k)). Pt electrocatalysts should have half-wave potentials $\left(E_{1 / 2}\right)$ in the order of low-index facets $(100)<(111)<(110)<$ high-index facets (311) for ORR in the $\mathrm{HClO}_{4}$ system [198-200]; however, the Pt multicubes achieve high ORR activity but are enclosed with high $\{100\}$ surface coverage. This exceptionally high ORR performance is enabled by the low contact resistance of a large flat $\{100\}$ surface, which has been supported by electrochemical impedance spectroscopy (EIS) measurements (Fig. 3(l)).

\subsection{High-index facets}

Since the 1970s, fundamental investigations on the single-crystal surfaces of bulk Pt have revealed that high-index planes exhibit much higher catalytic activity than low-index planes, such as $\{111\},\{100\}$ and even $\{110\}$, which usually act as distinct catalytic active sites for breaking chemical bonds [199-204]. After the pioneering work of synthesizing cubic and tetrahedral Pt nanoparticles by El-Sayed and co-workers [205], tremendous efforts have been devoted to prepare metal nanocrystals with different shapes by changing metal precursors, reducing reagents, stabilizing reagents, and solvents [72,137,141,145,206-214]. In recent years, intensive studies on electrocatalysis have been performed using metal nanocrystals with well-defined morphologies and high-index facets, which exhibit significantly enhanced catalytic performance relative to their counterparts with low-index facets [137,209-214]. Thus far, the metal nanocrystals bounded by 

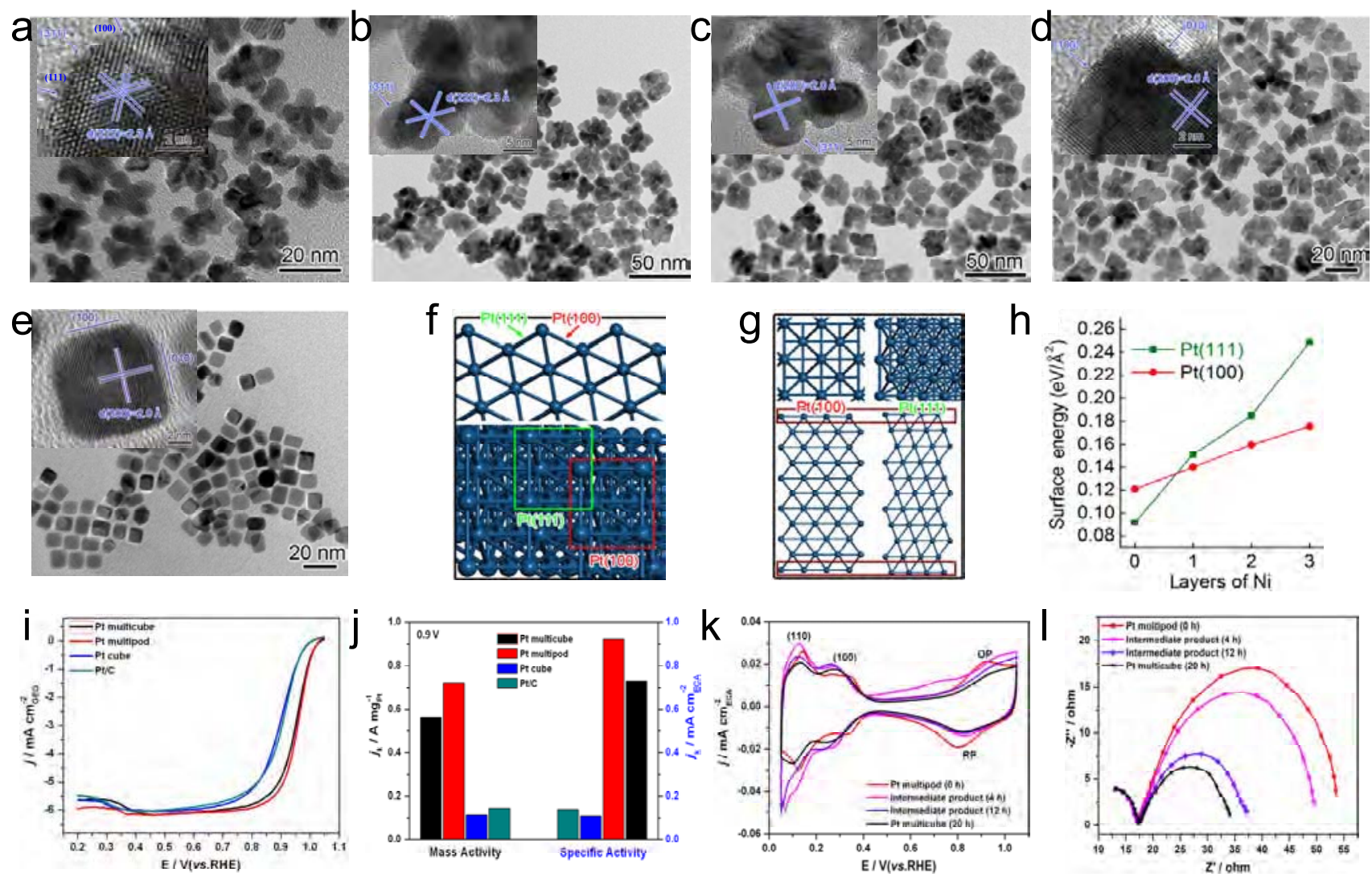

Fig. 3. (a)-(d) TEM and HRTEM images showing the morphological evolution from Pt multipods to multicubes in the presence of $\mathrm{Ni}^{2+}$ cations for 0 , 4, 12 and $20 \mathrm{~h}$. (e) TEM and HRTEM images of Pt nanocubes used as a reference sample for the electrochemical measurements. (f) Top and side views of Pt (311) surface consisting of Pt (100) (in red box) and Pt (111) (in green box) surface. (g) Top and side views of Pt (111) and Pt (100) slabs. The atoms in brown boxes are the atoms in the outermost Pt layer, which will be substituted by Ni in the calculations. (h) Dependence of surface formation energy on Ni coverage for Pt (111) and Pt (100). (i) ORR polarization curves and (j) mass activity and specific activity at 0.9 V versus RHE in $\mathrm{O}_{2}$-saturated $0.1 \mathrm{~mol} / \mathrm{L} \mathrm{HClO}_{4}$ solution at a scan rate of $20 \mathrm{mV} / \mathrm{s}$ and a rotation speed of 1600 revolutions per minute (rpm). (k) Blank CV curves recorded for different evolution samples at a scan rate of $20 \mathrm{mV} / \mathrm{s}$ and (l) EIS Nyquist plots of the electrodes made from different evolution samples at a bias of $-0.25 \mathrm{~V}$ in Ar-saturated $0.1 \mathrm{~mol} / \mathrm{L} \mathrm{HClO}_{4}$ solution. Reproduced with permission from Ref. [197].

high-index facets can be obtained through various wet-chemistry routes, such as oxidation etching, epitaxial growth, galvanic replacement, templating, de-alloying, electrochemistry, amine or ion-assisting, and manipulating reaction kinetics or thermodynamics. These nanocrystals are classified into two types in terms of the elemental compositions: monometallic (e.g., Pt, Pd and $\mathrm{Au}$ ) nanocrystals and multimetallic (including bimetallic) nanostructures [137,209-214]. For instance, unique Pt nanocrystals with high-index facets, such as tetrahexahedrons, concave polyhedrons and concave nanocubes, all show improved electrocatalytic activity and stability for formic acid oxidation, ethanol oxidation and ORR, respectively $[145,215,216]$. Fabricating Pt-based bimetallic or multimetallic nanostructures, such as PtPd, PtAu, PtFe, PtNi, PtCo, PtAg, PtCu, PtPdCu and PtPdAu, enclosed by high-index facets in the forms of alloys or core-shell structures is another key approach to boost the PEMFC electrocatalytic performance [80,120,165,217-226].

Investigating the development of metal nanocrystals bounded by high-index facets, it is straightforward to conclude that high-index facets possess a large number of terraces, steps, kinks, edges, vertexes and corners, and as a result, they have more low-coordinated active sites on the surface to enable high electrocatalytic activities as compared with low-index facets. For this reason, the preparation of high-index facets represents a highly important solution to improve the electrocatalytic performance of metal nanocrystals.

Towards the formation of high-index facets, we have employed oxidation etching to modulate the branched growth of Pt nanocrystals by simply adjusting the concentration of $\mathrm{HCl}$. This modification of etching strength can simultaneously tailor several important parameters in the synthesis, including the structures of seeds, the growth sites on the seeds and the rates of atomic addition on the seeds. As a result, tunable $\mathrm{Pt}$ branched structures, including tripods, tetrapods, hexapods and octopods, can be selectively obtained in a single system with identical chemical environment (Figs. 4(a)-(e)) [7]. The tunable structures of Pt branched nanocrystals provide a platform to investigate the effect of branches on their electrocatalytic performance in formic acid oxidation. The blank CVs clearly show that $\mathrm{Pt}$ hexapods and octopods have higher active surface areas and roughness than those of Pt/C catalysts (Fig. 4(f)). Surface area-specific activities toward formic acid oxidation are in the order of octopods $>$ hexapods $>$ tetrapods $>$ tri- 

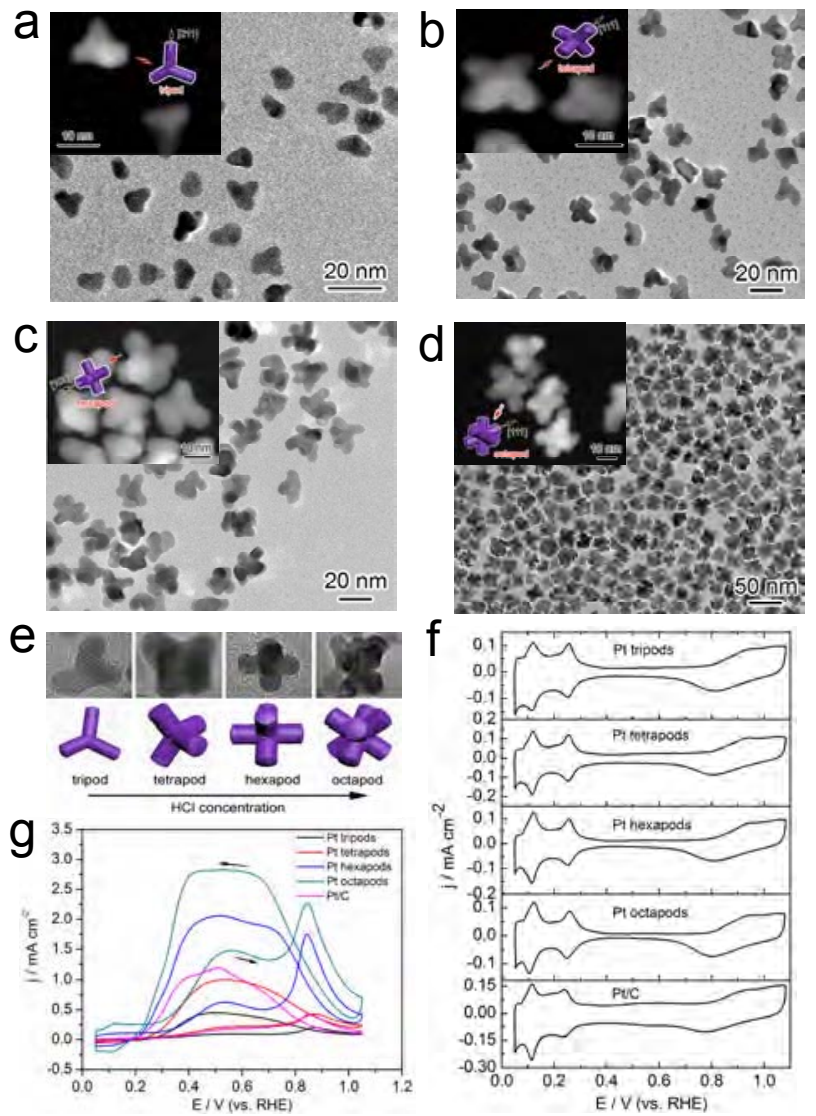

Fig. 4. TEM and STEM images of Pt tripods (a), tetrapods (b), hexapods (c) and octopods (d) prepared in the presence 0, 112.5, 225, 675 $\mathrm{mmol} / \mathrm{L} \mathrm{HCl}$, respectively. (e) Schematic for the shape dependence of Pt branched nanocrystals on $\mathrm{HCl}$ concentrations. (f) Blank CVs of electrodes composed of Pt tripods, tetrapods, hexapods and octopods, in $0.5 \mathrm{~mol} / \mathrm{L} \mathrm{H}_{2} \mathrm{SO}_{4}$ solution at a scan rate of $50 \mathrm{mV} / \mathrm{s}$. (g) Surface area-specific activities towards formic acid oxidation at electrodes composed of Pt tripods, tetrapods, hexapods and octopods, in $0.5 \mathrm{~mol} / \mathrm{L}$ $\mathrm{H}_{2} \mathrm{SO}_{4}+0.1 \mathrm{~mol} / \mathrm{L} \mathrm{HCOOH}$ solution at a scan rate of $50 \mathrm{mV} / \mathrm{s}$. Reproduced with permission from Ref. [7].

pods, and the onset potentials are slightly negatively shifted in the same order (Fig. 4(g)). The superior electrocatalytic performance of Pt octopods to their counterparts is ascribed to their high densities of $\{311\}$ and $\{211\}$ stepped surfaces.

Alternatively, we can form high-index facets on nanocrystal surface by inducing uneven anisotropic growth. For instance, we have obtained a class of unique five-fold twinned structures-Pd nanotapers by manipulating the anisotropic growth kinetics. The Pd nanotapers enriched with $\{311\}$ and $\{611\}$ high-index facets exhibit high electrochemical activities so that they can react with $\mathrm{HAuCl}_{4}$ through galvanic replacement to form $\mathrm{Au}$ islands on the surface, whereas other low-index Pd nanocrystals cannot [227]. We have further systematically investigated their structure-property relationships in electrocatalytic formic acid oxidation. The electrocatalytic performance of Pd nanocrystals is observed to increase in the order of octahedrons < nanowires < nanocubes < nanotapers. The results prove that the electrocatalytic activities of Pd nanocrystals are mainly determined by surface facets in the order of $\{111\}<$ $\{100\}<$ high-index facets [193].

\section{Interface engineering for electrocatalysts}

The electrocatalytic reaction also occurs at active sites on the interface as well as the surface of the nanocatalyst. The interfaces in hybrid structures are the locations relevant to electronic structures, charge transport and species exchange, whose design should be crucial to promoting their electrocatalytic performance. In addition, the interfaces can serve as active sites for electrocatalytic reactions in specific cases (particularly for exposed interfaces). In this section, we will discuss interface engineering through three different combinations and mechanisms.

\subsection{Fabricating multimetallic nanostructures}

Multimetallic (including bimetallic) nanostructures can be formed with two different configurations: hybrid structures and alloys which both can interface with different compositions, electronic structures, $d$-band depths, atomic arrangements and functional sites. Development of multimetallic nanostructures has become a widely used approach to improve the electrocatalytic performance [159-167]. To reduce Pt usage, our research group has developed a selective-activation method to synthesize Pd-Pt concave nanocubes (Figs. 5(a)-(d)) [228]. In this approach, we firstly selectively activate the corners and edges of Pd nanocubes by $\mathrm{HCl}$ etching, and then perform Pt epitaxial growth at the activated sites by controlling Pt
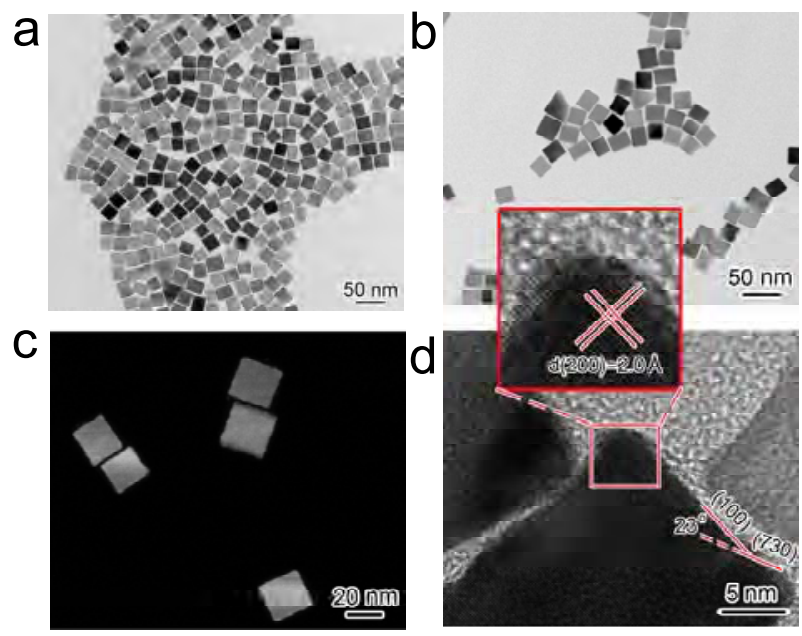

e

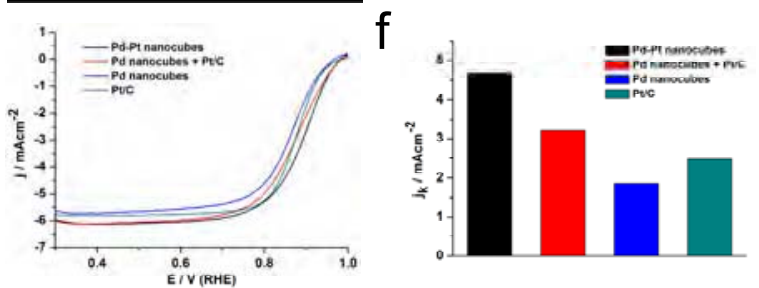

Fig. 5. (a) TEM image of the Pd nanocube seeds used for Pt epitaxial growth. TEM (b), STEM (c) and HRTEM (d) images of the PdPt nanocubes obtained through $\mathrm{HCl}$ surface activation and Pt epitaxial growth. (e) ORR polarization curves for the four samples in an $\mathrm{O}_{2}$-saturated $0.1 \mathrm{~mol} / \mathrm{L} \mathrm{HClO}_{4}$ solution with a sweep rate of $20 \mathrm{mV} / \mathrm{s}$ and a rotation rate of $1600 \mathrm{rpm}$. (f) Kinetic current densities ( $\left.j_{\mathrm{k}}\right)$ at $0.9 \mathrm{~V}$ versus RHE for the four samples normalized with reference to the geometric area of a GC RDE. Reproduced with permission from Ref. [228]. 
diffusion and growth rates [229]. As a result, the Pd-Pt concave nanocubes with a very limited amount of Pt (only $3.3 \mathrm{wt} \%$ ) on Pd nanocrystals can be obtained. The Pd-Pt concave nanocubes display a high specific activity of $4.7 \mathrm{~mA} \mathrm{~cm}-2$ for electrocatalytic ORR, which is 2.5 and 1.9 times greater than those of $\mathrm{Pd}$ nanocubes and Pt/C catalysts, respectively (Figs. 5(e), (f)). The Pd-Pt interface and $\{730\}$ high-index facets should be the key to the catalytic performance optimization. This method also offers the possibility of fabricating high-performance and low-cost nanocatalysts through controllable growth of noble metals on the surface of base metal nanocrystals by simply modifying the surface and interface conditions.

Alloying represents another approach to fabricate multimetallic nanostructures, providing a platform for performance tuning through atomic interfacing. In the synthesis of $\mathrm{Cu}$ nanocrystals, $\mathrm{Cu}$ nanocubes with small sizes are likely made of $\mathrm{Cu}_{2} \mathrm{O}$ rather than $\mathrm{Cu}[230,231]$. To improve their resistance to oxidation, we should alloy $\mathrm{Cu}$ with more passive metals. For this reason, we have successfully synthesized a series of small-scale and well-defined $\mathrm{Cu}_{x} \mathrm{Pt}_{100-x}$ alloy nanocubes with a relatively broad range of compositions and high $\mathrm{Cu}$ contents by precisely controlling the stabilizing/capping agents, reducing agents and reaction rates (Figs. 6(a)-(f)) [232]. The $\mathrm{Cu}_{x} \mathrm{Pt}_{100-x}$ nanocubes, with a consistent size of $10 \mathrm{~nm}$, offer an ideal platform to study
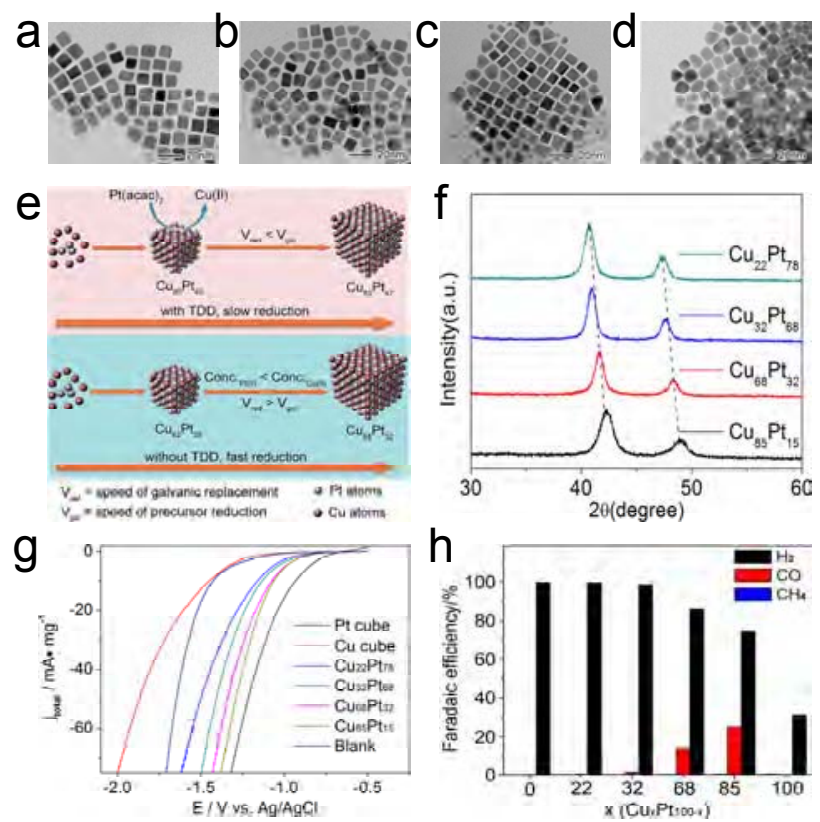

Fig. 6. TEM images of $\mathrm{Cu}_{22} \mathrm{Pt}_{78}$ (a), $\mathrm{Cu}_{32} \mathrm{Pt}_{68}$ (b), $\mathrm{Cu}_{68} \mathrm{Pt}_{32}$ (c) and $\mathrm{Cu}_{85} \mathrm{Pt}_{15}$ (d) nanocubes. (e) Schematic illustrating the growth mechanisms for the $\mathrm{Cu}_{x} \mathrm{Pt}_{100-x}$ nanocubes prepared in the presence or absence of TDD, taking the comparison of $\mathrm{Cu}_{68} \mathrm{Pt}_{32}$ (with TDD) with $\mathrm{Cu}_{53} \mathrm{Pt}_{47}$ (without TDD) as an example. (f) XRD patterns of $\mathrm{Cu}_{x} \mathrm{Pt}_{100-x}$ nanocubes with different compositions. (g) Electrocatalytic $\mathrm{CO}_{2}$ reduction performance recorded on $\mathrm{Cu}_{x} \mathrm{Pt}_{100-x}$ nanocubes with different compositions benchmarked against pure $\mathrm{Pt}$ nanocubes and pure $\mathrm{Cu}$ nanocubes with a blank electrode as a reference. (h) Faradaic efficiencies of the different-composition $\mathrm{Cu}_{x} \mathrm{Pt}_{100-x}$ nanocubes measured at $-1.75 \mathrm{~V}$ for $0.5 \mathrm{~h}$, benchmarked against pure $\mathrm{Pt}$ nanocubes and pure $\mathrm{Cu}$ nanocubes (electrolyte: $0.5 \mathrm{~mol} / \mathrm{L} \mathrm{KHCO}_{3}, \mathrm{CO}_{2}$ purged). Reproduced with permission from Ref. [232]. the composition-dependent effects on the electrocatalytic $\mathrm{CO}_{2}$ reduction related to the fuel generation for PEMFCs. The $\mathrm{Cu}_{x} \mathrm{Pt}_{100-x}$ nanocubes exhibit improved catalytic activities and gradually positive-shifted onset potentials in the electrocatalysis of the $\mathrm{CO}_{2}$ reduction reaction with increasing $\mathrm{Cu}$ content; however, pure $\mathrm{Cu}$ nanocrystals cannot survive from oxidation (Figs. 6(g), (h)). Thus, alloying of $\mathrm{Cu}$ nanostructures with Pt can largely improve their chemical stability, and this atomic interfacing may also potentially lower the decomposition activation energy of formate up to $13 \%$ [233].

\subsection{Loading on $2 D$ materials}

2D materials may have prominent geometrical, mechanical, thermal and electrical characteristics as well as exhibit excellent solubility, dispersion and adhesion. For this reason, we have used 2D materials, such as graphene, as support materials to fabricate unique metal-based hybrid structures. As such, we have further achieved the optimization of electrocatalytic performance, taking advantage of the merits of components and their synergistic effects.

Based on the synthesis of Pt branched nanostructures [7], we have developed a modified protocol for synthesizing Pt highly concave cubic nanocrystals (Pt HCCs) [8]. The Pt HCCs with $\{311\},\{100\}$ and $\{111\}$ facets display excellent activity and durability in electrocatalytic ORR, in sharp contrast to the commercial Pt/C catalysts. In particular, Pt HCCs have achieved a half-wave potential $\left(E_{1 / 2}\right)$ of $0.960 \mathrm{~V}$, which is comparable to that observed for the most active porous Pt-Ni catalyst reported in the literature [234]. To further improve the ORR performance of Pt HCCs, we have assembled the Pt HCCs on reduced graphene oxide ( $r \mathrm{GO}$ ) to form Pt HCCs-rGO hybrid structures (Figs. 7(a), (b)). In the hybrid structures, Pt HCCs enclosed by $\{311\}$ high-index facets are well supported on the $r \mathrm{GO}$ substrate with clear interfaces along the $\{100\}$ direction (Figs. 7(c)-(g)). The Pt HCCs-rGO hybrid structures exhibit mass activity of $-0.847 \mathrm{~A} / \mathrm{mgt}_{\mathrm{Pt}}$ and specific activity of $-1.02 \mathrm{~mA} / \mathrm{cm}^{2}$, which are 5.7-fold and 7.0-fold greater than those of $\mathrm{Pt} / \mathrm{C}$, respectively. Impressively, the half-wave potential has been improved to $0.967 \mathrm{~V}$ by the integration of Pt HCCs with $r G 0$, which is among the highest ORR $E_{1 / 2}$ values for non-alloy $\mathrm{Pt}$ catalysts at present. After durability tests, the Pt HCCs-rGO hybrid structures show electrochemically active area loss $(6.8 \%)$ in contrast to Pt HCCs (11.2\%) and Pt/C (19.5\%). The results indicate that Pt HCCs- $r$ GO hybrid structures have very high activity and durability for ORR (Figs. 7(h), (i)). The Pt-rGO interface may have made contributions to enhance electron conductivity, promote catalyst-electrode adhesion as well as suppress the agglomeration and oxidation erosion of catalysts [188-190].

In parallel, we have also successfully fabricated PtPd nanocages-rGO hybrid structures by a three-step synthetic process, using Pd nanocubes as templates and $r \mathrm{GO}$ nanosheets as supports [235]. In the synthesis, Pd nanocubes are grown on $r$ GO nanosheets, followed by epitaxial growth of Pt shells and etching removal of Pd cubic cores (Fig. 8). In the hybrid structures, the cubic nanocages that are enclosed by five Pt $\{100\}$ 

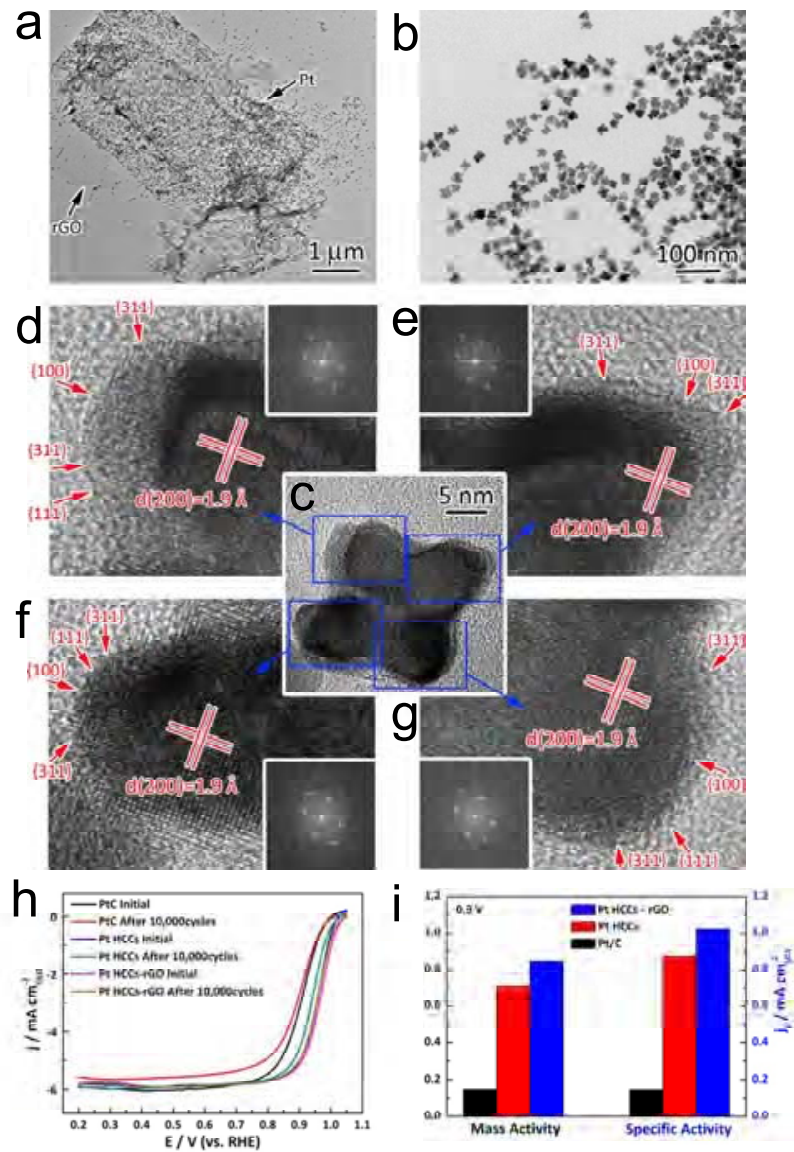

Fig. 7. (a, b) TEM images of Pt HCCs-rGO hybrid structures at different magnifications. (c)-(g) HRTEM images of a HCC supported on the $r \mathrm{GO}$ substrate, focused on each single corner. The insets show the corresponding Fourier-transformed diffraction patterns. (h) ORR polarization curves of Pt/C, Pt HCCs and Pt HCCs-rGO samples before and after 10,000 cycles. (i) Mass activity and specific activity at $0.9 \mathrm{~V}$ versus RHE. (h, i) Measurements in an $\mathrm{O}_{2}$-saturated $0.1 \mathrm{~mol} / \mathrm{L} \mathrm{HClO}_{4}$ solution with a sweep rate of $20 \mathrm{mV} / \mathrm{s}$ and a rotation rate of $1600 \mathrm{rpm}$. Reproduced with permission from Ref. [8].

faces with some pinholes have direct contact with $r$ GO through the other face. The achieved half-wave potential of $0.953 \mathrm{~V}$ are shown to be significantly higher than other counterparts in ORR electrocatalysis. The mass activity of $0.534 \mathrm{~A} / \mathrm{mg}_{\mathrm{Pt}}$ and specific activity of $0.482 \mathrm{~mA} / \mathrm{cm}^{2}$ are 4.4 times and 3.9 times greater than those of $\mathrm{Pt} / \mathrm{C}$, respectively. In comparison with $\mathrm{Pt}$ nanocubes and Pd-Pt core-shell nanocubes supported on $r \mathrm{GO}$, we have concluded that both the hollow structure, which increases surface area, and the presence of trace Pd, which prevents Pt dissolution and oxidation erosion, contribute to the ORR performance enhancement, in addition to the roles of the Pt-rGO interface that have been discussed above.

\subsection{Using interfacial polarization}

Surface charge state is a highly important parameter to catalytic activities, as it can affect molecular adsorption and species-catalyst charge transfer. For instance, the graphene doped a

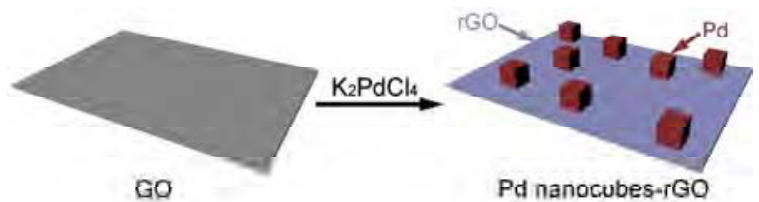

GQ

$P d$ nanocubes $r G Q$
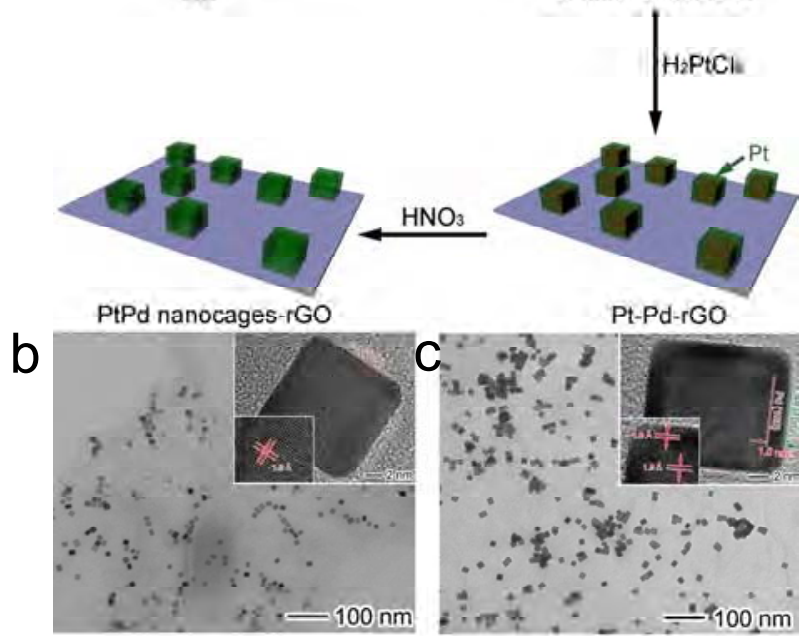

Pt-Pd-rGO

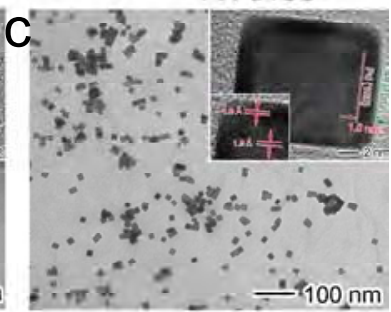

d

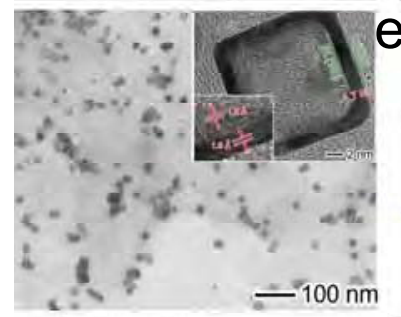

e

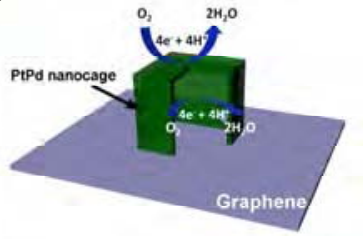

f
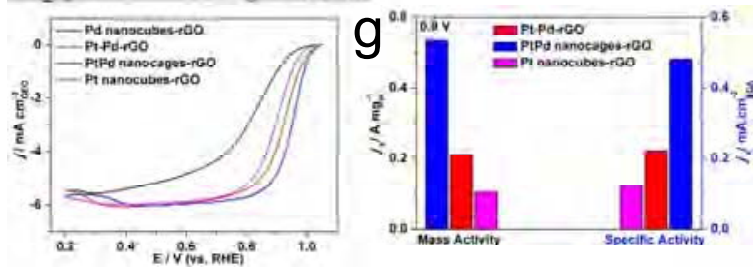

Fig. 8. (a) Illustration for the three-step synthesis of PtPd nanocages- $r$ GO hybrid structures. TEM and HRTEM (inset) images of Pd nanocubes-rGO (b), Pd-Pt-rGO (c), and PtPd nanocages-rGO (d) hybrid structures. (e) Illustration of PtPd nanocages-rGO hybrid structure for ORR electrocatalysis. (f) ORR polarization curves of as-obtained catalysts. (g) Mass activity and specific activity of Pt-based catalysts at $0.9 \mathrm{~V}$ versus RHE. Reproduced with permission from Ref. [235].

with nitrogen has shown enhanced activities in ORR owing to the electronegativity difference between $\mathrm{N}$ and C [236,237]. Thus far, a set of different approaches have been developed to tune the surface charge state of catalysts including polarization. Originally, the polarization can be induced by the external electric field or ferroelectric substrates [238,239]. Most recently, we have demonstrated that interfacial polarization may take place when two materials with different work functions are put together. As long as the travel length is short enough, the charges accumulated by the polarization at the interface can be extended to the surface, modifying the surface charge state of catalysts as a surface polarization. We have implemented this strategy in various reaction systems such as CO oxidation [143]. 

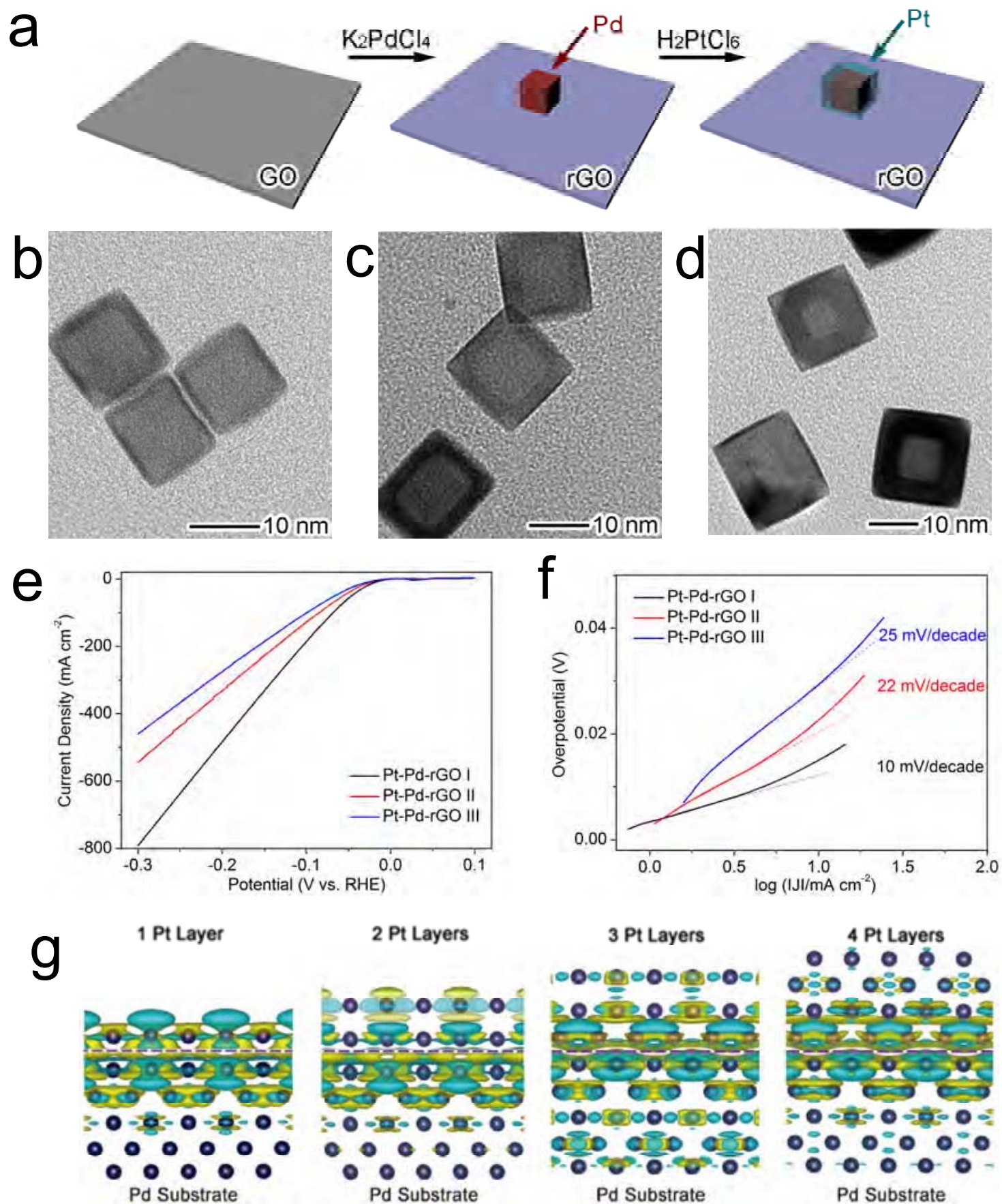

Fig. 9. (a) Schematic illustration for the synthesis of Pt-Pd-rGO structures. TEM images of Pt-Pd-rGO I (b), Pt-Pd-rGO II (c) and Pt-Pd-rGO III (d) with tunable Pt thickness. Polarization curves (e) and Tafel plots (f) of Pt-Pd-rGO I, II, and III. (g) Differential charge density by first-principles simulations illustrating the alterations of electron distributions with the Pt thickness. The olive and cyan areas represent the increase and decrease in electron density, respectively. In the simulations, Pd substrates are covered by various layers of Pt atoms to assess the dependence of surface polarization on Pt thickness. Reproduced with permission from Ref. [9].

In terms of electrocatalysis, we have demonstrated this concept through the design of Pt-Pd-rGO stack nanostructures for electrocatalytic HER (Fig. 9) [9]. The Pt-Pd- $r$ GO nanostructures with a well-defined cubic profile (namely, $\{100\}$ facets) are fabricated by a two-step synthetic process that involves the in-situ growth of Pd nanocubes and selective coating of Pt cubic shells on the Pd (Figs. 9(a)-(d)). In the hybrid structures, the bottom surface of Pd nanocubes is in contact with the $r \mathrm{GO}$ and thus not covered by Pt atoms. The contacting Pd and Pt components have different work functions, which causes a flow of electrons from Pd to Pt to equilibrate the electron Fermi distribution and induces polarization at their interface. Once the distance between the polarized interface and the reactive surface is reduced to the atomic level (1-2 atomic layers), negative 
charges will accumulate on the surface in favor of HER (Fig. $9(\mathrm{~g}))$. Thus it is important to tune the thickness of Pt shells for achieving effective surface polarization. In the synthesis, we can realize the tunable thickness of Pt shells on Pd nanocubes by simply altering the ratio of added Pd-rGO to Pt precursor. As a result, a series of Pt-Pd-rGO hybrid structures (namely, Pt-Pd-rGO I, II, and III) with increased Pt shell thickness have been obtained, providing an ideal platform for HER investigations. As anticipated, the current densities at the same potential are found to be in the order of Pt-Pd-rGO I > Pt-Pd-rGO II > Pt-Pd-rGO III with a nearly zero overpotential. Meanwhile, both the over-potentials and Tafel slopes are in the reverse order, further verifying that the HER performance can be enhanced with Pt thickness reduction (Figs. 9(e), (f)). This design enables reducing Pt usage while achieving high HER performance.

\section{Outlook}

The electrocatalytic activities of metallic nanocrystals can be facilely tuned by tailoring their surface facets (low-index facets, Fig. 10(a) versus high-index facets, Fig. 10(b)). To further improve their activity and durability, one can form core-shell structures (Fig. 10(c)) or alloys (Fig. 10(d)) by integrating multiple metals together, or/and load the nanocrystals on the supports of other materials (Fig. 10(e)). From the discussions, it is not difficult to recognize that there remain many challenges in

a

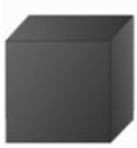

cube

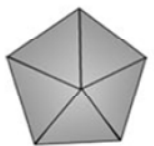

decahedron

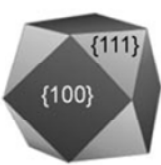

cuboctahedron

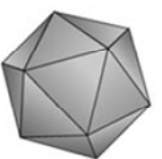

icosahedron

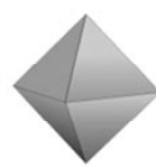

octahedron

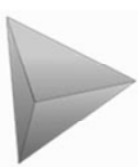

tetrahedron

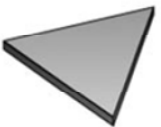

triangular plate

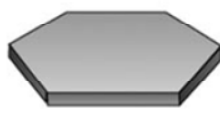

hexagonal plate b

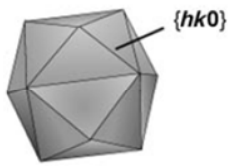

tetrahexahedron

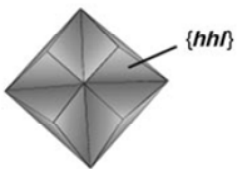

trisoctahedron

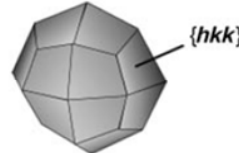

trapezohedron

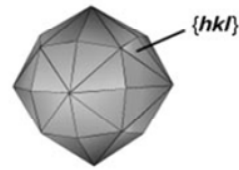

hexoctahedron

C
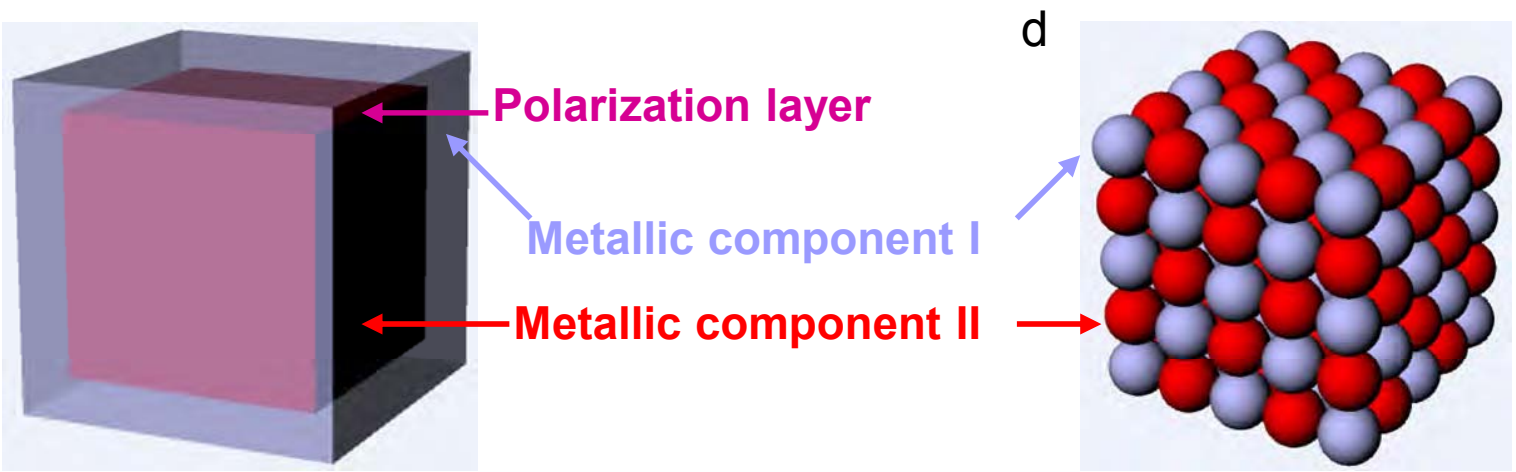

e

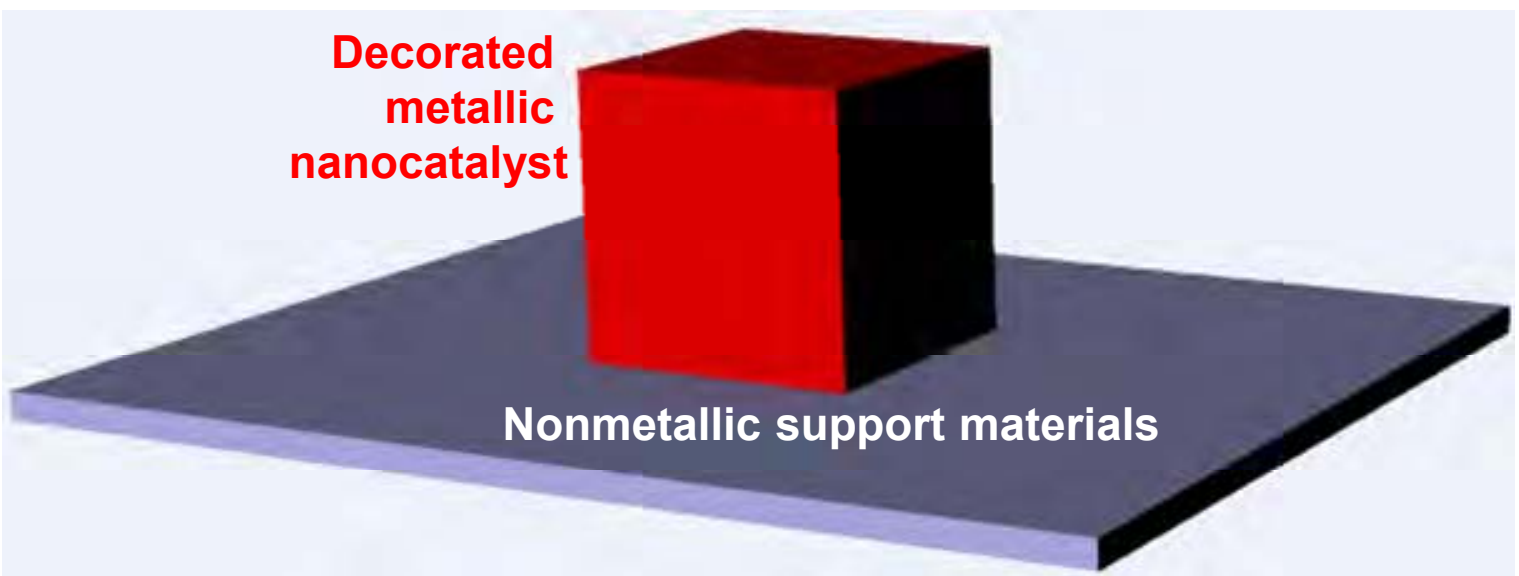

Fig. 10. (a) Conventional shapes of $f c c$ metals whose surfaces are enclosed by $\{100\}$ and/or $\{111\}$ facets. Black and gray colors represent the $\{100\}$ and $\{111\}$ facets, respectively. (b) Unconventional shapes of $f c c$ metals whose surfaces are enclosed by high-index facets. The Miller indices $\{h k l\}$ obey the order $h>k>l$. (a, b) Reproduced with permission from Ref. [141]. Schematic configurations for the surfaces and interfaces in a bimetallic core-shell structure (c), an alloy (d) and a metal nanocrystal loaded on a nonmetal support (e). 
this research field. Here, we name some issues that have been brought to our attention from the previous research in the field:

(1) Thus far, the control over surface facets still heavily relies on the use of capping agents. The presence of capping agents on a nanocrystal surface inevitably has various effects on the catalytic activities. In our research, we mainly employ oxygen plasma cleaning and blank electrochemical cycles to remove organic residues. According to the blank CV characterizations, this method should be able to clean the nanocrystal surface; however, it cannot be guaranteed that the nanocrystal surface structure is fully preserved after the cleaning process given the difficulty of performing HRTEM on the samples stripped from electrodes. Thus, it is imperative to develop new methods for facet control. Essentially, oxidative etching should be a relatively clean technique for modifying the nanocrystal surface as it does not introduce organic ligands onto the surface. The remaining problem for this technique is that capping agents are still indispensable for oxidative etching although the same capping agent can be used in an etching system to obtain various nanostructures.

(2) The quality of the interface in hybrid structures should attract sufficient attention from the electrocatalysis research community. This issue has actually been well-recognized in photocatalysis research, as any defects at the interface may become charge recombination centers. In terms of electrocatalysis, charges also need to travel across the interfacial boundary of hybrid structures, in which interfacial defects may scatter or trap electrons. Both syntheses and characterizations would be the focus of research towards the improvement of interface quality.

(3) The sample uniformity and dispersion for hybrid structures are often critical issues to limiting their electrocatalytic performance. In particular, when metal nanocrystals are loaded on 2D nanomaterials, the nanocrystals can hardly be uniformly dispersed on the nanosheets. The aggregation of samples may reduce the number of active sites as well as affect charge transport and species exchange. Improving the integration quality of hybrid structures would be another focus of research, which may arise from surface functionalization and chemical bonding.

We have provided an overview of electrocatalyst design with a focus on surface and interface engineering, using our own researches as examples for demonstration. This review will aid in the engineering of efficient and cost-effective nanocatalysts in electrocatalysis.

\section{References}

[1] Grubb W T. Nature, 1963, 198: 883

[2] Stamenkovic V R, Fowler B, Mun B S, Wang G F, Ross P N, Lucas C A, Markovic N M. Science, 2007, 315: 493

[3] Stamenkovic V R, Mun B S, Arenz M, Mayrhofer K J J, Lucas C A, Wang G F, Ross P N, Markovic N M. Nat Mater, 2007, 6: 241

[4] Zhou Z Y, Tian N, Li J T, Broadwell I, Sun S G. Chem Soc Rev, 2011, 40: 4167

[5] Zhang J, Sasaki K, Sutter E, Adzic R R. Science, 2007, 315: 220

[6] Wu G, More K L, Johnston C M, Zelenay P. Science, 2011, 332: 443

[7] Ma L, Wang C M, Gong M, Liao L W, Long R, Wang J G, Wu D, Zhong W, Kim M J, Chen Y X, Xie Y, Xiong Y J. ACS Nano, 2012, 6: 9797

[8] Wang C M, Ma L, Liao L W, Bai S, Long R, Zuo M, Xiong Y J. Sci Rep, 2013, 3: 2580

[9] Bai S, Wang C M, Deng M S, Gong M, Bai Y, Jiang J, Xiong Y J. Angew Chem Int Ed, 2014, 53: 12120

[10] Koenigsmann C, Wong S S. Energy Environ Sci, 2011, 4: 1161

[11] Shen Q M, Min Q H, Shi J J, Jiang L P, Zhang J R, Hou W H, Zhu J J. J Phys Chem C, 2009, 113: 1267

[12] Qiu J D, Wang G C, Liang R P, Xia X H, Yu H W. J Phys Chem C, 2011, 115: 15639

[13] Choi K S, McFarland E W, Stucky G D. Adv Mater, 2003, 15: 2018

[14] Xiao Z L, Han C Y, Kwok W K, Wang H H, Welp U, Wang J, Crabtree G W.J Am Chem Soc, 2004, 126: 2316

[15] Kim P, Epstein A K, Khan M, Zarzar L D, Lipomi D J, Whitesides G M, Aizenberg J. Nano Lett, 2012, 12: 527

\section{Graphical Abstract}

Chin. J. Catal., 2015, 36: 1476-1493 doi: 10.1016/S1872-2067(15)60911-1

\section{Recent advances in surface and interface engineering for electrocatalysis}

Chengming Wang *, Song Bai, Yujie Xiong*

University of Science and Technology of China

This review discusses how to rationally design and fabricate noble metal-based nanostructures as electrocatalysts towards low cost and high performance, from the viewpoint of surface and interface engineering.

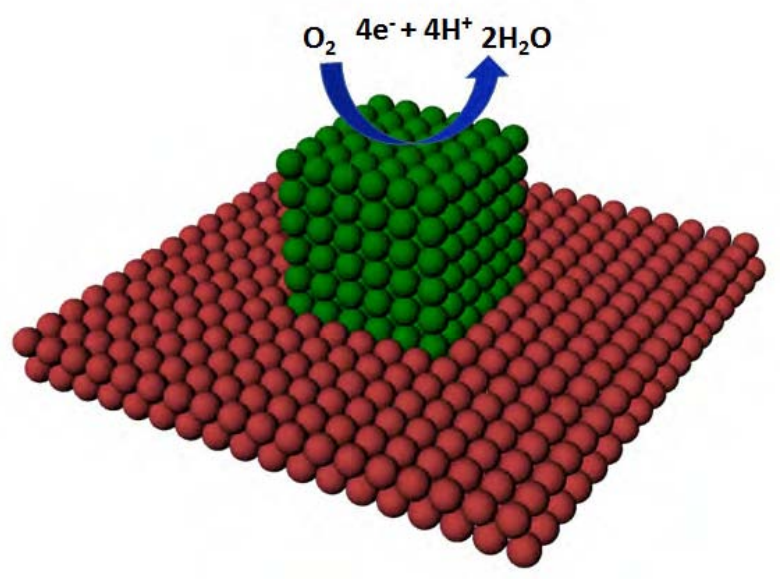


[16] Allred D B, Sarikaya M, Baneyx F, Schwartz D T. Nano Lett, 2005, 5: 609

[17] Lim S K, Kim M Y, Oh T S. Thin Solid Films, 2009, 517: 4199

[18] Lin E C, Cole J J, Jacobs H O. Nano Lett, 2010, 10: 4494

[19] Carreón-González C E, Medina J D L T, Piraux L, Encinas A. Nano Lett, 2011, 11: 2023

[20] Day T M, Unwin P R, Wilson N R, Macpherson J V. J Am Chem Soc, 2005, 127: 10639

[21] Koenigsmann C, Santulli A C, Gong K P, Vukmirovic M B, Zhou W P, Sutter E, Wong S S, Adzic R R. J Am Chem Soc, 2011, 133: 9783

[22] Heyderman L J, Schift H, David C, Ketterer B, Auf der Maur M, Gobrecht J. Microelectronic Engineering, 2001, 57-58: 375

[23] Park S, Boo H, Lee S Y, Kim H M, Kim K B, Kim H C, Chung T D. Electrochim Acta, 2008, 53: 6143

[24] Papageorgiou N, Maier W F, Grätzel M. J Electrochem Soc, 1997, 144: 876

[25] Protsenko V S, Danilov F I. Metal Finishing, 2010, 108: 28

[26] Iwasita T, Xia X H, Liess H-D, Vielstich W. J Phys Chem B, 1997, 101: 542

[27] García H, Roth H D. Chem Rev, 2002, 102: 3947

[28] Chng L L, Erathodiyil N, Ying J Y. Acc Chem Res, 2013, 46: 1825

[29] Rosca V, Duca M, de Groot M T, Koper M T M. Chem Rev, 2009, 109: 2209

[30] Trasatti S. Int J Hydrogen Energy, 1995, 20: 835

[31] Du J L, Chen Z F, Chen C C, Meyer T J. J Am Chem Soc, 2015, 137: 3193

[32] Jin L H, Fang Y X, Wen D, Wang L, Wang E K, Dong S J. ACS Nano, 2011, 5: 5249

[33] Wang C M, Cui H. Luminescence, 2007, 22: 35

[34] Dong Y P, Gao T T, Zhou Y, Chu X F, Wang C M. Spectrochim Acta A, 2015, 134: 225

[35] Dasari R, Zamborini F P. J Am Chem Soc, 2008, 130: 16138

[36] Shao Y Y, Wang J, Wu H, Liu J, Aksay I A, Lin Y H. Electroanalysis, 2010, 22: 1027

[37] Zhu C Z, Yang G H, Li H, Du D, Lin Y H. Anal Chem, 2015, 87: 230

[38] Wang J. Chem Rev, 2008, 108: 814

[39] Schulte A, Schuhmann W. Angew Chem Int Ed, 2007, 46: 8760

[40] Qian T C, Wang Y X. Med Biol Eng Comput, 2010, 48: 1023

[41] Zhou M, Dong S J. Acc Chem Res, 2011, 44: 1232

[42] Sage A T, Besant J D, Lam B, Sargent E H, Kelley S O. Acc Chem Res, 2014, 47: 2417

[43] Joglekar M, Trewyn B G. Biotechnol J, 2013, 8: 931

[44] Li C M, Hu W H. J Electroanal Chem, 2013, 688: 20

[45] Dong Y P, Zhou Y, Ding Y, Chu X F, Wang C M. Anal Methods, 2014, 6: 9367

[46] Dong Y P, Gao T T, Chu X F, Chen J, Wang C M. J Lumin, 2014, 154 350

[47] Kim E, Kim K, Yang H, Kim Y T, Kwak J. Anal Chem, 2003, 75: 5665

[48] Brillas E, Sirés I, Oturan M A. Chem Rev, 2009, 109: 6570

[49] Zhou M H, Dai Q Z, Lei L C, Ma C A, Wang D H. Environ Sci Technol, 2005, 39: 363

[50] Panizza M, Bocca C, Cerisola G. Water Res, 2000, 34: 2601

[51] Murphy O J, Hitchens G D, Kaba L, Verostko C E. Water Res, 1992, 26: 443

[52] Kim H, Boysen D A, Newhouse J M, Spatocco B L, Chung B, Burke P J, Bradwell D J, Jiang K, Tomaszowska A A, Wang K L, Wei W F, Ortiz L A, Barriga S A, Poizeau S M, Sadoway D R. Chem Rev, 2013, 113: 2075

[53] Wang Z L, Xu D, Xu J J, Zhang X B. Chem Soc Rev, 2014, 43: 7746

[54] Li Y G, Dai H J. Chem Soc Rev, 2014, 43: 5257

[55] Black R, Lee J H, Adams B, Mims C A, Nazar L F. Angew Chem Int $E d, 2013,52: 392$
[56] Winter M, Brodd R J. Chem Rev, 2004, 104: 4245

[57] Šimpraga R P, Conway B E. Electrochim Acta, 1998, 43: 3045

[58] Aricò A S, Bruce P, Scrosati B, Tarascon J M, van Schalkwijk W. Nat Mater, 2005, 4: 366

[59] You B, Jiang N, Sheng M L, Sun Y J. Chem Commun, 2015, 51: 4252

[60] Walter M G, Warren E L, McKone J R, Boettcher S W, Mi Q X, Santori E A, Lewis N S. Chem Rev, 2010, 110: 6446

[61] Licht S, Wang B, Mukerji S, Soga T, Umeno M, Tributsch H. J Phys Chem B, 2000, 104: 8920

[62] Kudo A, Miseki Y. Chem Soc Rev, 2009, 38: 253

[63] Kim T W, Choi K S. Science, 2014, 343: 990

[64] Borup R, Meyers J, Pivovar B, Kim Y S, Mukundan R, Garland N, Myers D, Wilson M, Garzon F, Wood D, Zelenay P, More K, Stroh K, Zawodzinski T, Boncella J, McGrath J E, Inaba M, Miyatake K, Hori M, Ota K, Ogumi Z, Miyata S, Nishikata A, Siroma Z, Uchimoto Y, Yasuda K, Kimijima K, Iwashita N. Chem Rev, 2007, 107: 3904

[65] Zhang H W, Shen P K. Chem Rev, 2012, 112: 2780

[66] Wang A L, He X J, Lu X F, Xu H, Tong Y X, Li G R. Angew Chem Int Ed, 2015, 54: 3669

[67] Faber M S, Lukowski M A, Ding Q Kaiser N S, Jin S. J Phys Chem C, 2014, 118: 21347

[68] Hamnett A. Catal Today, 1997, 38: 445

[69] Bing Y H, Liu H S, Zhang L, Ghosh D, Zhang J J. Chem Soc Rev, 2010, 39: 2184

[70] Gandhi H S, Graham G W, McCabe R W.J Catal, 2003, 216: 433

[71] Xin H L, Holewinski A, Schweitzer N, Nikolla E, Linic S. Top Catal, 2012, 55: 376

[72] Xia Y N, Xiong Y J, Lim B, Skrabalak S E. Angew Chem Int Ed, 2009, 48: 60

[73] Murray C B, Sun S H, Doyle H, Betley T. MRS Bulletin, 2001, 26: 985

[74] Marks L D. Rep Prog Phys, 1994, 57: 603

[75] Wulff G. Zeitschrift Fur Krystallographie Und Mineralogie, 1901, 34: 449

[76] LaMer V K, Dinegar R H. J Am Chem Soc, 1950, 72: 4847

[77] Wang Z L.J Phys Chem B, 2000, 104: 1153

[78] Wang C M, Zhong W, Liao L W, Xiong Y J. Sci Sin Chim (王成名, 钟 玮, 廖玲文, 熊宇杰. 中国科学: 化学), 2013, 43:1614

[79] Xia B Y, Yan Y, Wang X, Lou X W. Mater Horiz, 2014, 1: 379

[80] Nie Y, Li L, Wei Z D. Chem Soc Rev, 2015, 44: 2168

[81] Wu Y E, Wang D S, Li Y D. Chem Soc Rev, 2014, 43: 2112

[82] You H J, Yang S C, Ding B J, Yang H. Chem Soc Rev, 2013, 42: 2880

[83] Bai S, Xiong Y J. Sci Adv Mater, 2015, DOI:10.1166/sam.2015. 2261

[84] O'Hayre R P, Cha S W, Colella W. Prinz F B. Fuel Cell Fundamentals. New York: John Wiley and Sons, 2006. 8

[85] Steele B C H, Heinzel A. Nature, 2001, 414: 345

[86] Litster S, McLean G. J Power Sources, 2004, 130: 61

[87] Winter M, Brodd R J. Chem Rev, 2004, 104: 4245

[88] Cropper M A J, Geiger S, Jollie D M. J Power Sources, 2004, 131: 57

[89] Iwasita T. Electrochim Acta, 2002, 47: 3663

[90] Kreuer K D. J Membrane Sci, 2001, 185: 29

[91] Jiang K, Zhang H X, Zou S Z, Cai W B. Phys Chem Chem Phys, 2014, 16: 20360

[92] O'Mullane A P. Nanoscale, 2014, 6: 4012

[93] Bond G C. Surf Sci, 1985, 156: 966

[94] Nesselberger M, Ashton S, Meier J C, Katsounaros I, Mayrhofer K J J, Arenz M.J Am Chem Soc, 2011, 133: 17428

[95] Peng Z M, Yang H. J Am Chem Soc, 2009, 131: 7542

[96] Peng Z M, Yang H. Nano Today, 2009, 4: 143

[97] Sun Y F, Gao S, Lei F C, Xie Y. Chem Soc Rev, 2015, 44: 623

[98] Sun Y F, Gao S, Xie Y. Chem Soc Rev, 2014, 43: 530 
[99] Zhang X D, Xie Y. Chem Soc Rev, 2013, 42: 8187

[100] Huang X Q, Tang S H, Mu X L, Dai Y, Chen G X, Zhou Z Y, Ruan F X, Yang Z L, Zheng N F. Nat Nanotechnol, 2011, 6: 28

[101] Li H, Chen G X, Yang H Y, Wang X L, Liang J H, Liu P X, Chen M, Zheng N F. Angew Chem Int Ed, 2013, 52: 8368

[102] Jang K, Kim H J, Son S U. Chem Mater, 2010, 22: 1273

[103] Duan H H, Yan N, Yu R, Chang C R, Zhou G, Hu H S, Rong H P, Niu Z Q Mao J J, Asakura H, Tanaka T, Dyson P J, Li J, Li Y D. Nat Commun, 2014, 5: 3093

[104] Yin A X, Liu W C, Ke J, Zhu W, Gu J, Zhang Y W, Yan C H. J Am Chem Soc, 2012, 134: 20479

[105] Huang X, Li S Z, Huang Y Z, Wu S X, Zhou X Z, Li S Z, Gan C L, Boey F, Mirkin C A, Zhang H. Nat Commun, 2011, 2: 292

[106] Cao Z W, Fu H B, Kang L T, Huang L W, Zhai T Y, Ma Y, Yao J N. Mater Chem, 2008, 18: 2673

[107] Wang X L, Wu B H, Chen G X, Zhao Y, Liu P X, Dai Y, Zheng N F. Nanoscale, 2014, 6: 6798

[108] Saleem F, Zhang Z C, Xu B, Xu X B, He P L, Wang X. J Am Chem Soc, 2013, 135: 18304

[109] Liang H Y, Li Z P, Wang W Z, Wu Y S, Xu H X. Adv Mater, 2009, 21: 4614

[110] Lv C, Zhang X Y, Mu C L, Wu D, Wang C M, Zhang Q L. J Nanosci Nanotechnol, 2015, 15: 2761

[111] Lim B, Xia Y N. Angew Chem Int Ed, 2011, 50: 76

[112] Rezaei S J T, Bide Y, Nabid M R. Synth Metals, 2011, 161: 1414

[113] Zhang H, Xia X H, Li W Y, Zeng J, Dai Y Q Yang D R, Xia Y N. Angew Chem Int Ed, 2010, 49: 5296

[114] Cao C B, Chen Z, An X Q, Zhu H S.J Phys Chem C, 2008, 112: 9

[115] Okamoto M, Fujigaya T, Nakashima N. Small, 2009, 5: 735

[116] Lou X W, Archer L A, Yang Z. Adv Mater, 2008, 20: 3987

[117] Guo Y G, Hu J S, Wan L J. Adv Mater, 2008, 20: 2878

[118] Bianchini C, Shen P K. Chem Rev, 2009, 109: 4183

[119] Peng Z M, You H J, Wu J B, Yang H. Nano Lett, 2010, 10: 1492

[120] Chen C, Kang Y J, Huo Z Y, Zhu Z W, Huang W Y, Xin H L, Snyder J D, Li D G, Herron J A, Mavrikakis M, Chi M F, More K L, Li Y D, Markovic N M, Somorjai G A, Yang P D, Stamenkovic V R. Science, 2014, 343: 1339

[121] Li R, Hu J H, Deng M S, Wang H L, Wang X J, Hu Y L, Jiang H L, Jiang J, Zhang Q, Xie Y, Xiong Y J. Adv Mater, 2014, 26: 4783

[122] Nohra B, Moll H E, Rodriguez Albelo L M, Mialane P, Marrot J, Mellot-Draznieks C, O’Keeffe M, Biboum R N, Lemaire J, Keita B, Nadjo L, Dolbecq A. J Am Chem Soc, 2011, 133: 13363

[123] Wittstock A, Wichmann A, Bäumer M. ACS Catal, 2012, 2: 2199

[124] Yan M, Jin T N, Ishikawa Y, Minato T, Fujita T, Chen L Y, Bao M, Asao N, Chen M W, Yamamoto Y. J Am Chem Soc, 2012, 134: 17536

[125] Cherevko S, Kulyk N, Chung C H. Langmuir, 2012, 28: 3306

[126] Schaefer A, Ragazzon D, Wittstock A, Walle L E, Borg A, Bäumer M, Sandell A.J Phys Chem C, 2012, 116: 4564

[127] Déronzier T, Morfin F, Massin L, Lomello M, Rousset J L. Chem Mater, 2011, 23: 5287

[128] Guo D J, Ding Y. Electroanal, 2012, 24: 2035

[129] Yan X L, Meng F H, Xie Y, Liu J G, Ding Y. Sci Rep, 2012, 2: 941

[130] Xu C X, Su J X, Xu X H, Liu P P, Zhao H J, Tian F, Ding Y. J Am Chem Soc, 2007, 129: 42

[131] Xu C X, Wang L Q, Wang R Y, Wang K, Zhang Y, Tian F, Ding Y. Adv Mater, 2009, 21: 2165

[132] Gu X H, Cong X, Ding Y. ChemPhysChem, 2010, 11: 841

[133] Xu C X, Wang R Y, Chen M W, Zhang Y, Ding Y. Phys Chem Chem
Phys, 2010, 12: 239

[134] Gu X H, Xu L Q, Tian F, Ding Y. Nano Res, 2009, 2: 386

[135] Ge X B, Yan X L, Wang R Y, Tian F, Ding Y. J Phys Chem C, 2009, 113: 7379

[136] Quan Z W, Wang Y X, Fang J Y. Acc Chem Res, 2013, 46: 191

[137] Yu Y, Zhang Q B, Liu B, Lee J Y.J Am Chem Soc, 2010, 132: 18258

[138] Xiong Y J, Xia Y N. Adv Mater, 2007, 19: 3385

[139] Li Y, Boone E, El-Sayed M A. Langmuir, 2002, 18: 4921

[140] Xie S F, Choi S I, Xia X H, Xia Y N. Current Opinion Chem Eng, 2013, 2: 142

[141] Xiong Y J, Wiley B, Xia Y N. Angew Chem Int Ed, 2007, 46: 7157

[142] Wang L L, Ge J, Wang A L, Deng M S, Wang X J, Bai S, Li R, Jiang J, Zhang Q, Luo Y, Xiong Y J. Angew Chem Int Ed, 2014, 53: 5107

[143] Bai Y, Zhang W H, Zhang Z H, Zhou J, Wang X J, Wang C M, Huang W X, Jiang J, Xiong Y J. J Am Chem Soc, 2014, 136: 14650

[144] Lebedeva N P, Rodes A, Feliu J M, Koper M T M, van Santen R A. J Phys Chem B, 2002, 106: 9863

[145] Tian N, Zhou Z Y, Sun S G, Ding Y, Wang Z L. Science, 2007, 316: 732

[146] Taylor H S. Proc R Soc London Ser A, 1925, 108: 105

[147] Marks L D. Rep Prog Phys, 1994, 57: 603

[148] Tian G L, Zhang Q, Zhang B S, Jin Y G, Huang J Q Su D S, Wei F. Adv Funct Mater, 2014, 24: 5956

[149] Xing J, Jiang H B, Chen J F, Li Y H, Wu L, Yang S, Zheng L R, Wang H F, Hu P, Zhao H J, Yang H G.J Mater Chem A, 2013, 1: 15258

[150] Kibsgaard J, Chen Z B, Reinecke B N, Jaramillo T F. Nat Mater, 2012, 11: 963

[151] Lertanantawong B, O'Mullane A P, Surareungchai W, Somasundrum M, Burke L D, Bond A M. Langmuir, 2008, 24: 2856

[152] Nagle L C, Garbarino S, Burke L D. ECS Trans, 2010, 25: 3

[153] Hammer B. Top Catal, 2006, 37: 3

[154] Liu Y W, Cheng H, Lyu M J, Fan S J, Liu Q H, Zhang W S, Zhi Y D, Wang C M, Xiao C, Wei S Q, Ye B J, Xie Y. J Am Chem Soc, 2014, 136: 15670

[155] Xie J F, Zhang H, Li S, Wang R X, Sun X, Zhou M, Zhou J F, Lou X W, Xie Y. Adv Mater, 2013, 25: 5807

[156] Roxlo C B, Deckman H W, Gland J, Cameron S D, Chianelli R R. Science, 1987, 235: 1629

[157] Chianelli R R, Ruppert A F, Behal S K, Kear B H, Wold A, Kershaw R. J Catal, 1985, 92: 56

[158] Xin H L, Holewinski A, Schweitzer N, Nikolla E, Linic S. Top Catal, 2012, 55: 376

[159] Sun S H, Murray C B, Weller D, Foiks L, Moser A. Science, 2000, 287: 1989

[160] Habas S E, Lee H, Radmilovic V, Somorjai G A, Yang P D. Nat Mater, 2007, 6: 692

[161] Esposito D V, Hunt S T, Stottlemyer A L, Dobson K D, McCandless B E, Birkmire R W, Chen J G G. Angew Chem Int Ed, 2010, 49: 9859

[162] Wang L L, Johnson D D. J Am Chem Soc, 2009, 131: 14023

[163] Loukrakpam R, Luo J, He T, Chen Y S, Xu Z C, Njoki P N, Wanjala B N, Fang B, Mott D, Yin J, Klar J, Powell B, Zhong C J. J Phys Chem C, 2011, 115: 1682

[164] Liu Y, Chi M F, Mazumder V, More K L, Soled S, Henao J D, Sun S H. Chem Mater, 2011, 23: 4199

[165] Hwang S J, Kim S K, Lee J G, Lee S C, Jang J H, Kim P, Lim T H, Sung Y E, Yoo S J.J Am Chem Soc, 2012, 134: 19508

[166] Xia B Y, Wu H B, Li N, Yan Y, Lou X W, Wang X. Angew Chem Int Ed, 2015, 54: 3797

[167] Ferrando R, Jellinek J, Johnston R L. Chem Rev, 2008, 108: 845 
[168] Roy R, Komamenis S, Roy D M. Mater Res Soc Symp Proc, 1984, 32: 347

[169] Xi G C, Ye J H, Ma Q, Su N, Bai H, Wang C. J Am Chem Soc, 2012, 134: 6508

[170] Yu T, Zeng J, Lim B, Xia Y N. Adv Mater, 2010, 22: 5188

[171] Lee H, Yoon S W, Kim E J, Park J. Nano Lett, 2007, 7: 778

[172] Zheludkevich M L, Salvado I M, Ferreira M G S. J Mater Chem, 2005, 15: 5099

[173] Joo J, Park D H, Jeong M Y, Lee Y B, Kim H S, Choi W J, Park Q H, Kim H J, Kim D C, Kim J. Adv Mater, 2007, 19: 2824

[174] Gurrappa I, Binder L. Sci Technol Adv Mater, 2008, 9: 043001

[175] Rieter W J, Taylor K M L, Lin W B. J Am Chem Soc, 2007, 129: 9852

[176] Xiong Y J, Chen J Y, Wiley B, Xia Y N, Aloni S, Yin Y D. J Am Chem Soc, 2005, 127: 7332

[177] Wiley B J, Herricks T, Sun Y G, Xia Y N. Nano Lett, 2004, 4: 1733

[178] Wiley B J, Xiong Y J, Li Z Y, Yin Y D, Xia Y N. Nano Lett, 2006, 6: 765

[179] Xiong Y J, Cai H, Wiley B J, Wang J G, Kim M J, Xia Y N. J Am Chem Soc, 2007, 129: 3665

[180] Caruso F, Caruso R A, Moehwald H. Science, 1998, 282: 1111

[181] Walcarius A. Chem Soc Rev, 2013, 42: 4098

[182] Zhao D, Budhi S, Koodali R T. ACS Symp Ser, 2010, 1045: 97

[183] Ren Y, Ma Z, Bruce P G. Chem Soc Rev, 2012, 41: 4909.

[184] Walcarius A. Electroanalysis, 2008, 20: 711

[185] Yang J, Voiry D, Ahn S J, Kang D, Kim A Y, Chhowalla M, Shin H S. Angew Chem Int Ed, 2013, 52: 13751

[186] Tang H, Dou K P, Kaun C C, Kuang Q, Yang S H. J Mater Chem A, 2014, 2: 360

[187] Kong D S, Wang H T, Lu Z Y, Cui Y. J Am Chem Soc, 2014, 136, 4897

[188] Zhang Y B, Tan Y W, Stormer H L, Kim P. Nature, 2005, 438: 201

[189] Lee C, Wei X, Kysar J W, Hone J. Science, 2008, 321, 385

[190] Geim A K. Science, 2009, 324: 1530

[191] Gong C, McDonnell S, Qin X, Azcatl A, Dong H, Chabal Y J, Cho K, Wallace R M. ACS Nano, 2014, 8: 642

[192] Zhang H, Jin M S, Xiong Y J, Lim B, Xia Y N. Acc Chem Res, 2013, 46 1783

[193] Wang C M, Bai Y, Wang L L, Long R, Liu D, Deng M S, Xiong Y J. Sci Sin Chim (王成名, 柏战, 王利利, 龙舟, 刘东, 邓明森, 熊宇杰. 中国科学: 化学), 2013, 43: 744

[194] Long R, Mao K K, Ye X D, Yan W S, Huang Y B, Wang J Y, Fu Y, Wang X S, Wu X J, Xie Y, Xiong Y J. J Am Chem Soc, 2013, 135: 3200

[195] Li B, Long L, Zhong X L, Bai Y, Zhu Z J, Zhang X, Zhi M, He J W, Wang C M, Li Z Y, Xiong Y J. Small, 2012, 8: 1710

[196] Long R, Wu D, Li Y P, Bai Y, Wang C M, Song L, Xiong Y J. Nano Res, 2015, DOI: 10.1007/s12274-015-0722-1.

[197] Ma L, Wang C M, Xia B Y, Mao K K, He J W, Wu X J, Xiong Y J, Lou X W. Angew Chem Int Ed, 2015, 54: 5666

[198] Komanicky V, Menzel A, You H.J Phys Chem B, 2005, 109: 23550

[199] Kuzume A, Herrero E, Feliu J M. J Electroanal Chem, 2007, 599: 333

[200] Macia M D, Campina J M, Herrero E, Feliu J M. J Electroanal Chem, 2004, 564: 141

[201] Somorjai G A, Blakely D W. Nature, 1975, 258: 580

[202] Somorjai G A. Chemistry in Two Dimensions: Surfaces, Cornell University Press, Ithaca, 1981.

[203] Somorjai G A. Science, 1985, 227: 902

[204] Sun S G, Chen A C, Huang T S, Li J B, Tian Z W. J Electroanal Chem, 1992, 340: 213

[205] Ahmadi T S, Wang Z L, Green T G, Henglein A, El-Sayed M A. Sci- ence, 1996, 272: 1924

[206] Tian N, Zhou Z Y, Sun S G. J Phys Chem C, 2008, 112: 19801

[207] Lee H, Habas S E, Kweskin S, Butcher D, Somorjai G A, Yang P D. Angew Chem Int Ed, 2006, 45: 7824

[208] Sun Y G, Xia Y N. Science, 2002, 298: 2176

[209] Tian N, Zhou Z Y, Yu N F, Wang L Y, Sun S G. J Am Chem Soc, 2010, 132: 7580

[210] Jin M S, Zhang H, Xie Z X, Xia Y N. Angew Chem Int Ed, 2011, 50: 7850

[211] Zhang J, Langille M R, Personick M L, Zhang K, Li S Y, Mirkin C A.J Am Chem Soc, 2010, 132: 14012

[212] Wang F, Li C H, Sun L D, Wu H S, Ming T, Wang J F, Yu J C, Yan C H. J Am Chem Soc, 2011, 133:1106

[213] Zhang L, Zhang J W, Kuang Q Xie S F, Jiang Z Y, Xie Z X, Zheng L S. J Am Chem Soc, 2011, 133: 17114

[214] Kim D, Lee Y W, Lee S B, Han S W. Angew Chem Int Ed, 2012, 51: 159

[215] Huang X Q, Zhao Z P, Fan J M, Tan Y M, Zheng N F. J Am Chem Soc, 2011, 133: 4718

[216] Yu T, Kim D Y, Zhang H, Xia Y N. Angew Chem Int Ed, 2011, 50: 2773

[217] Lim B, Jiang M, Camargo P H C, Cho E C, Tao J, Lu X M, Zhu Y M, Xia Y N. Science, 2009, 324: 1302

[218] Lee H, Habas S E, Somorjai G A, Yang P D. J Am Chem Soc, 2008, 130: 5406

[219] Teng X W, Feygenson M, Wang Q, He J Q, Du W X, Frenkel A I, Han W Q, Aronson M. Nano Lett, 2009, 9: 3177

[220] Kim J, Lee Y, Sun S H. J Am Chem Soc, 2010, 132: 4996

[221] Wu Y E, Cai S F, Wang D S, He W, Li Y D. J Am Chem Soc, 2012, 134: 8975

[222] Wu J B, Zhang J L, Peng Z M, Yang S C, Wagner F T, Yang H. J Am Chem Soc, 2010, 132: 4984

[223] Fu G T, Xia B Y, Ma R G, Chen Y, Tang Y W, Lee J M. Nano Energy, 2015, 12: 824

[224] Yin A X, Min X Q, Zhu W, Liu W C, Zhang Y W, Yan C H. Chem Eur J, 2012, 18: 777

[225] Wang L, Yamauchi Y. Chem Mater, 2011, 23: 2457

[226] Sasaki K, Naohara H, Choi Y M, Cai Y, Chen W F, Liu P, Adzic R R. Nat Commun, 2012, 3: 1115

[227] Wang C M, Wang L L, Long L, Ma L, Wang L M, Li Z Q Xiong Y J.J Mater Chem, 2012, 22, 8195

[228] Bai Y, Long R, Wang C M, Gong M, Li Y R, Huang H, Xu H, Li Z Q, Deng M S, Xiong Y J.J Mater Chem A, 2013, 1: 4228

[229] Narayanan R, El-Sayed M A. Nano Lett, 2004, 4: 1343

[230] Jin M S, He G N, Zhang H, Zeng J, Xie Z X, Xia Y N. Angew Chem Int Ed, 2011, 50: 10560

[231] van Hardeveld R, Hartog F. Surf Sci, 1969, 15: 189

[232] Zhao X Y, Luo B B, Long R, Wang C M, Xiong Y J. J Mater Chem A, 2015, 3: 4134

[233] Reilly J P, O'Connell D, Barnes C J. J Phys Condens Matter, 1999, 11: 8417

[234] Snyder J, Fujita T, Chen M W, Erlebacher J. Nat Mater, 2010, 9: 904

[235] Bai S, Wang C M, Jiang W Y, Du N N, Li J, Du J T, Long R, Li Z Q, Xiong Y J. Nano Res, 2015, DOI: 10.1007/s12274-015-0770-6

[236] Qu L T, Liu Y, Baek J B, Dai L M. ACS Nano, 2010, 4: 1321

[237] Kong X K, Chen C L, Chen Q W. Chem Soc Rev, 2014, 43: 2841

[238] Kolpak A M, Grinberg I, Rappe A M. Phys Rev Lett, 2007, 98: 166101

[239] Vayenas C G, Bebelis S, Ladas S. Nature, 1990, 343: 625 


\title{
电催化剂设计中表面和界面工程的最新进展
}

\author{
王成名 ${ }^{*}$, 柏 嵩, 熊宇杰 \\ 中国科学技术大学合肥微尺度物质科学国家实验室, 能源材料化学协同创新中心, 化学与材料科学学院, 安徽合肥 230026
}

摘要: 电催化已发展为一种涉及电化学、表面科学、材料科学和催化科学等众多科学分支的交叉学科和综合技术, 在工农业生产、 经济和国防建设、能源开发和环境保护等方面发挥了不可或缺的作用. 金属纳米催化剂的可控合成和创新构建, 极大地推动了电 催化的广泛应用和巨大进展. 过渡金属尤其是贵金属Pt、Pd等电催化剂, 在电催化中表现出良好的选择性、活性和稳定性, 很难 完全被其他材料所取代. 制约电催化可持续发展的瓶颈问题是, 如何设计、合成和构建高性能低成本的金属纳米催化剂. 为实现 这一目标, 人们付出了大量的努力并取得了一些可喜的进展. 电催化是发生在电解质与电极材料表面和界面的异相催化反应, 金 属纳米电催化剂的性能与其形貌、结构、尺寸和组成相关. 本文着力总结和探讨如何从表面工程和界面工程角度设计、合成和 构筑金属纳米结构及其复合结构, 以实现金属电催化剂性能和成本的双优化.

本文提出了在金属纳米结构及其复合结构的设计、合成和构筑过程中需要考虑的几个重要的表面和界面因素, 即表面面积、 表面晶面、活性位点和界面结构等. 首先, 有效表面面积越大, 越有利于电催化反应. 我们总结了增大催化剂有效活性面积的四种 有效方法, 包括减小颗粒尺寸、制成薄层二维纳米结构、增大粗粘度、形成中空、多孔或介孔及框架结构等. 其次, 表面晶面也 可决定电催化的性能. 我们简单总结了低指数晶面和高指数晶面在表面能、晶面形成和催化活性上的 “挑战与机遇”矛盾关系, 并 简要阐述了晶面选择性即晶面效应以及晶面与尺寸的依赖关系. 再次, 活性位点一般指的是低配位表面原子位点, 是电催化反应 的决定因素之一. 我们描述了活性位点与表面和界面结构特征、纳米晶表面晶面、表面缺陷和空穴、表面面积和粒子尺寸等的 依赖关系. 最后, 界面结构工程是调控电催化性能的最丰稔因素. 我们简述了界面结构的形成、分类及其对优化界面活性位点的 成分和几何结构、表面悬键和原子配位数、电子结构与电子传递、质子传输和物种交换等方面调控作用, 并在界面工程的基础上 推介了贵金属基复合结构的合成、组装的几种典型方式.

本文以具体示例的形式, 分别从表面工程和界面工程的角度, 扼要介绍了本课题组最近在甲酸氧化、氧还原、析氢等电催化 反应体系中贵金属基纳米结构及其复合纳米结构电催化剂的设计、合成与构筑的具体做法. 我们分别介绍了低指数晶面和高指 数晶面的表面设计对于提高催化剂性能的关键作用. 对于低指数晶面, 我们重点介绍了如何获得相似尺寸的不同表面晶面以研 究其晶面效应, 如何维持相同晶面调节尺寸以研究其尺寸效应, 如何建造与电极有良好电学接触的低指数晶面纳米结构, 以利于 提升其电催化性能. 对于高指数晶面, 介绍了几种形成高指数晶面的途径, 并阐明了其晶面对电催化性能的影响. 另一方面, 我们 从金属纳米结构及其复合结构的成分和结构调控策略介绍了界面构建对于提升电催化性能的奇妙作用,包括建造多金属纳米结 构、与二维材料负载组装和利用界面极化.

由此, 本文总结了表面和界面工程对于电催化剂设计、合成和构筑目前面临的三个关键挑战.

关键词: 合成; 表面工程; 界面工程; 电催化; 复合结构

收稿日期: 2015-03-29. 接受日期: 2015-05-28. 出版日期: 2015-09-20.

*通讯联系人. 电话: (0551)63606447; 传真: (0551)63606657; 电子信箱: chmwang@ustc.edu.cn

\#通讯联系人. 电话/传真: (0551)63606657; 电子信箱: yjxiong@ustc.edu.cn

基金来源: 国家自然科学基金 $(21101145,21471141)$; 国家“青年千人计划”; 中国科学院“百人计划”; 安徽省自然科学基金 (1508085MB24); 中央高校基本科研业务费专项资金(WK2060190025, WK2310000035).

本文的英文电子版由Elsevier出版社在ScienceDirect上出版(http://www.sciencedirect.com/science/journal/18722067). 